1 Jérémie Sage, Emmanuel Berthier, Marie-Christine Gromaire (2020). Modeling Soil Moisture

2 Redistribution and Infiltration Dynamics in Urban Drainage Systems, Journal of Hydrologic

3 Engineering, 04020041

4 The final publication is available at ASCE via http://dx.doi.org/10.1061/(ASCE)HE.1943-

$5 \quad \underline{5584.0001978}$

6 Copyright: (OAmerican Society of Civil Engineering 


\title{
MODELING SOIL MOISTURE REDISTRIBUTION AND INFILTRATION DYNAMICS IN URBAN DRAINAGE
}

\section{SYSTEMS}

\author{
Jérémie SAGE ${ }^{1}$, Emmanuel BERTHIER ${ }^{1}$, Marie-Christine GROMAIRE ${ }^{2}$. \\ ${ }^{1}$ Cerema, Equipe TEAM, 12 rue Teisserenc de Bort, F-78190, Trappes, France \\ ${ }^{2}$ ENPC, LEESU, Université Paris Est, UMR MA 102 - Agro ParisTech, 6-8 av. Blaise Pascal, 77455 Champs-sur- \\ Marne, France
}

\begin{abstract}
Hydrological modeling has become a common approach for the design of stormwater management strategies which, at the same time, increasingly rely on permeable and decentralized systems to mitigate the impacts of urbanization. In most applications, little attention is however paid to the temporal variability of infiltration fluxes resulting from soil moisture redistribution between rain events. In this study, a conceptual infiltration-redistribution model is introduced to investigate the importance of the description of infiltration fluxes for the modeling of sustainable urban drainage systems (SUDS). Model verification against numerical solution of Richards equation is first conducted. Performance indicators simulated with the model for a large range of infiltration scenarios are later compared to those obtained with simpler approaches, commonly used in urban hydrology. The model is shown to replicate at a low computational cost numerical solutions of Richards equation. Regarding SUDS modeling, results indicate that a correct description of the temporal variability of infiltration fluxes (1) may be needed for some configurations to assess longterm volume-reduction efficiencies and (2) is more generally required when examining frequencybased performance indicators.
\end{abstract}

KEYWORDS: Green-Ampt; Soil; Stormwater; Water content; Redistribution; Temporal

\section{INTRODUCTION}

On-site stormwater management, in relatively simple facilities such as ponds or swales, has been widely encouraged to minimize the adverse effects of urban discharges on surface waters. In this context, hydrological modeling has received significant attention and appears to be a relevant tool for the design and performance assessment of stormwater management practices. 
The efficiency of on-site stormwater management facilities largely originates from the runoff volume reduction associated with infiltration and evapotranspiration (Bressy et al. 2014). Significant pollution control may thus be achieved through the management of small events in simple permeable systems, using native soils. While an assessment of these processes is presumably needed for the development of efficient stormwater management strategies, the level of accuracy required for their description in modeling applications yet remains unclear.

The importance of continuous simulation to evaluate the performance of sustainable urban drainage systems (SUDS) is now well accepted (Fletcher et al. 2013; Salvadore et al. 2015). However, if the variability of rainfall events and initial storage conditions in such facilities is generally accounted for, the description of the infiltration process is yet seldom questioned and often relies on very simple conceptual models (Browne et al. 2008). Particularly, simulation of soil moisture variations from a rain event to another remains unusual, although changes in water content affect the infiltration process. Ignoring soil moisture redistribution generally avoids the use of complex unsaturated flow equations or the introduction of a detailed soil description and could possibly be relevant for such applications. Nonetheless, there is no evidence that this simplification does not lead to erroneous evaluation of the performance of stormwater management systems.

The Green and Ampt (1911) (GA) equation is a conceptual and physically-based model which has been widely adopted in both urban and general hydrology because of its simplicity and its ability to describe typical soil infiltration patterns, with high initial infiltration rates followed by a decrease to a steady-state value. In this model, infiltration rates depend upon the initial soil water content at the beginning of rain events which is often (especially in urban hydrology) assumed to remain unchanged from an event to another and set to a constant value such as field capacity (Abi Aad et al. 2010; Akan 2013; Heasom et al. 2006; Lee et al. 2013; Rosa et al. 2015).

Direct resolution of the unsaturated flow problem to evaluate the changes in soil moisture content (Richards' equation, 1931) would generally be cumbersome for simple applications such as the evaluation of stormwater management practices. It might as well precludes (or at least complicate) the use of optimization or sensitivity analysis techniques involving a large number of simulations (Brunetti et al. 2019), especially when a variety of conditions are considered in terms of surface boundary conditions and material properties (as discretization has to be adapted on a case by case basis). This approach can also become computationally demanding in the context of distributed models (Fatichi et al. 2016).

While relatively sophisticated alternative to Richards' equation have successfully been applied in general hydrology to simulate soil moisture redistribution, the models adopted in urban hydrology generally remain very simple. Most common approaches indeed rely on empirical equations (Lynn et al. 2018; Rossman 2010a) or assume gravity driven flow over a storage zone with homogeneous water content (Dussaillant et al. 2003; Her et al. 2017; Rossman 2010b) to account for the variability of initial moisture conditions in the GA model. Although the two aforementioned solutions have obvious limitations, their implications have rarely been 
discussed. The empirical redistribution equation implemented in the US-EPA SWMM model (Rossman 2010a) for instance does not account for evapotranspiration and presumably requires calibration. Similarly, the second methods involve unrealistic averaging of the soil moisture profile and neglect the effect of capillary forces on the redistribution process (Rossman 2010b).

Among the more detailed approaches adopted in watershed hydrology, extensions of the GA infiltration equation, that simulate the redistribution of the saturation profile during non-rainfall periods (Gowdish and Muñoz-Carpena 2009; Lai et al. 2015), have been shown to perform relatively well and appear as a promising alternative for the modeling of SUDS. These models were however not tested for such applications and exhibit some limitations due to their inability to replicate near-surface water content over long simulation periods (especially for coarse soils or under the effect of evapotranspiration, as shown in Ogden and Saghafian (1997).

In this paper, an improved infiltration-redistribution scheme (I2RS) is introduced to simulate the evolution of soil moisture content and infiltration fluxes within SUDS over a wide range of surface boundary conditions and for long period applications. The I2RS model was specifically developed to overcome the difficulties associated with the resolution of Richards' equation, for which convergence is generally not granted. The objectives of the study are: (1) to evaluate the applicability of the I2RS model and (2) to perform simulations with the I2RS model so as to assess the importance of a correct description of the temporal variability of infiltration fluxes in the context of SUDS modeling. The ability of I2RS to replicate infiltration rates as well as variations of water content near soil surface, for simple case studies and over longer simulation periods, is first checked against the numerical solution of Richards' equations for different soil types and magnitude of surface fluxes. The I2RS model is later adopted to simulate a large number of stormwater infiltration scenarios and to derive several volume-reduction efficiency indicators. The consequences of using as less accurate description of the temporal variability of infiltration are then examined by comparing the results associated with the I2RS model to those computed for a simpler redistribution scheme and under the "traditional" GA assumption of constant initial moisture content.

\section{REDISTRIBUTION OF THE GREEN-AMPT SATURATED PROFILE}

\section{THE GREEN-AMPT MODEL}

The Green-Ampt (GA) model can be used to compute infiltration-rates under ponded conditions into a homogeneous soil, assuming a piston displacement of the saturated profile (e.g. saturated zone delimitated by a sharp wetting front. Under ponded conditions, the infiltration rate $f_{\text {sup }}$ at the soil surface can be computed as:

$$
f_{\text {sup }}=K\left[1+\frac{H_{f}+z_{p}}{Z_{f}}\right]=K\left[1+\frac{\Delta \theta\left(H_{f}+z_{p}\right)}{F}\right]
$$


Where: $K=$ effective hydraulic conductivity often taken equal to saturated hydraulic conductivity $K_{s}\left(\left[\mathrm{~L} \cdot \mathrm{T}^{-1}\right]\right), \varkappa_{\phi}=$ ponding depth ([L]), $Z_{f}=$ vertical extension of the saturated profile $([\mathrm{L}]), \Delta \theta=\theta_{s}-\theta_{0}$, water deficit where $\theta_{s}=$ saturated water content and $\theta_{0}=$ initial water content, $F=\Delta \theta \times Z_{f}$ cumulative infiltration depth in the saturated profile ([L]), and $H_{f}=$ capillary pressure or suction head at the wetting front ([L]), which theoretically depends on $\theta_{0}$ (Stewart et al. 2013).

\section{WETTING PROFILE REDISTRIBUTION MODELS: STATE OF THE ART}

The existence of a wetting front, as described by the GA equation (although diffuse rather than sharp), during infiltration is supported by experimental and theoretical evidences. Once saturation of the soil surface stops, this wetting front continues to move downward, while the water content in the wetting profile decreases (Gardner et al. 1970) (cf. figure 1). Several extensions of the GA equation were thus developed, as alternatives to the resolution of Richards equation, to describe this movement of water in the soil during redistribution.
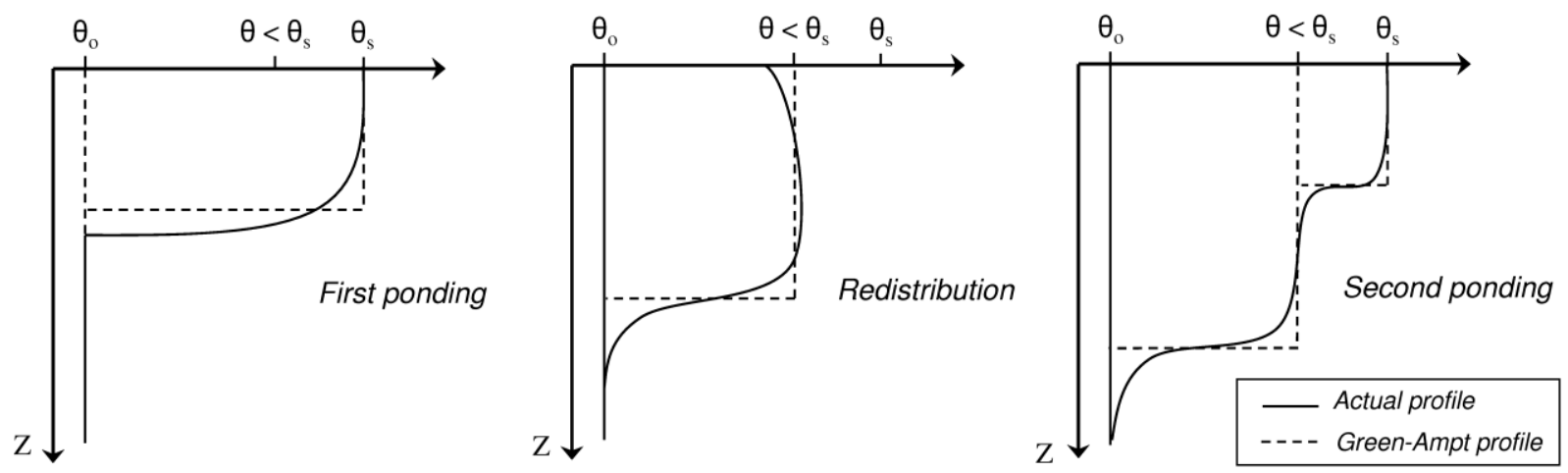

Figure 1. Redistribution of the saturated profile and creation of second saturation profile after redistribution (Ogden and Saghafian 1997)

Most of these "wetting profile redistribution models" result from vertical averaging of Darcy's law and derive from stochastic upscaling studies (Clapp et al. 1983; Dagan and Bresler 1983) or climate model applications (Milly 1986). Numerous variants of these simulation schemes have since then been proposed to simulate the movement of the wetting front during redistribution, accounting for distortion of the wetting profile (Corradini et al. 1997; Smith et al. 1993), or under the simpler piston-flow assumption (Govindaraju and Levent Kavvas 1993; Gowdish and Muñoz-Carpena 2009; Markar and Mein 1987; Ogden and Saghafian 1997).

Recent applications of the wetting profile redistribution formalism (Gowdish and Muñoz-Carpena 2009; Lai et al. 2015) consisted in extensions of the GAR (Green-Ampt with Redistribution) model developed by Ogden and Saghafian (1997). These methods were generally found to satisfactorily approximate the solutions of Richards' equation on an event basis, with relatively accurate replication of both infiltration fluxes and average water contents over the soil profile. 
Systematic deviations were however observed after few redistribution cycles, requiring the introduction of corrective terms for multi-storm applications (Gowdish and Muñoz-Carpena 2009; Ogden and Saghafian 1997). Another limitation of these models is the assumption of a monotonic moisture profile (systematic decrease of water content with depth) that precludes the representation of a faster drying of superficial soil layers under the action of redistribution or evapotranspiration.

The I2RS model presented in this article relies on a more general formulation of the redistribution process to simulate the variations of soil water content under the effect of gravity, capillary forces and evapotranspiration. The redistribution procedure is based on a specific component of the Event Based simulation Model (EBM) of Milly (1986) and coupled with the GA equation. Although adapted from the work of Milly (1986), the I2RS model differs in several respects from the original contribution:

- The influence of soil moisture conditions on infiltration fluxes was not accounted for in Milly's EBM, which relied on a simple Philips equation with constant sorptivity parameters (thus exhibiting a similar behavior for each rain event). Here, a complete and consistent coupling between the GA equation and Milly's redistribution scheme is introduced to account for the effect of redistribution.

- Because the purpose of the EBM model was the quantification of water and energy fluxes at the earth-atmosphere interface, a relatively complex description of evaporation based on the desorptivity concept was adopted. The effect of this process on the moisture profile was however very roughly accounted for (setting near-surface water content to a constant negligible value), as the model was not intended to provide realistic estimates of near-surface water contents. Conversely, the infiltrationredistribution scheme introduced afterwards incorporates a rather simple representation of evapotranspiration that nonetheless affects soil moisture content A further modification is also implemented to provide a more accurate description of near surface water content

The I2RS model shares similarities with previous GAR approaches (Gowdish and Muñoz-Carpena 2009; Ogden and Saghafian 1997), namely the coupling of the GA equation with a simplified method for the redistribution of the saturated profile. Two improvements are however introduced:

- I2RS relies on a specific procedure to simulate non-monotonic moisture profile associated with the faster drying of superficial soil layers and thus provides better water content estimates for the application of the GA equation

- In connection with the aforementioned procedure, I2RS incorporates a simple parameterization of evapotranspiration that interacts with near surface water content

(It is worth mentioning that I2RS exhibits two features of the more sophisticated and conceptually different “finite water content approaches" recently developed by Ogden et al. (2015) and Talbot and Ogden (2008), although it retains the relative simplicity of the GAR approach). 


\section{THE IMPROVED INFILTRATION-REDISTRIBUTION SCHEME (I2RS)}

The soil profile is described as a homogeneous domain, consisting of $n$ fronts delimitating $n+1$ soil layers (subscript $\mathrm{n}$ being associated with the uppermost front). Each front $i_{\in[;, n]}$ is characterized by an uniform water content $\theta_{i}$ and a depth of penetration denoted as $Z_{i}$ (cf. figure 2). The soil layer located beneath the lowermost front is assumed to have a constant water content $\theta_{0}$ and an infinite extension.

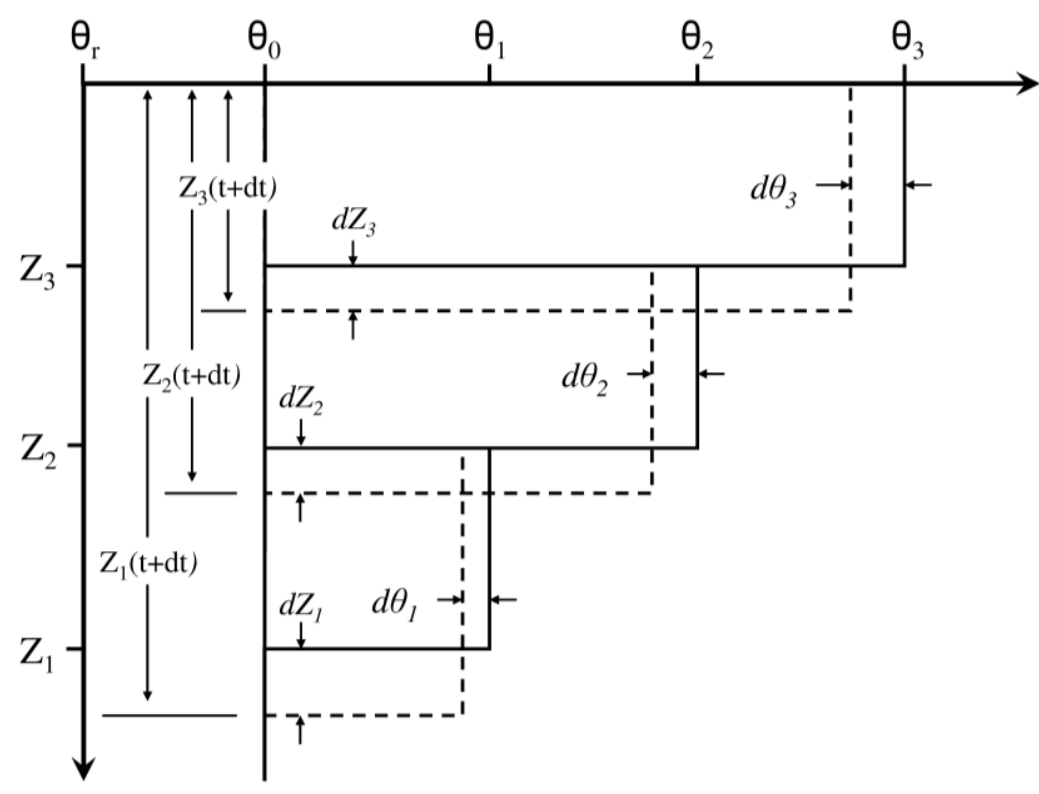

Figure 2. Water profile redistribution as represented in the conceptual multi-front redistribution model

The movement of fronts $n$ to 1 is governed by a set of ordinary differential equations for $\theta_{i}$ and $Z_{\iota}$ For $\theta_{n}=\theta_{s}$ these equations revert to the GA infiltration equation.

The approach adopted to carry out the coupling between the redistribution model and the GA equation is adapted from previous studies (Gowdish and Muñoz-Carpena 2009; Ogden and Saghafian 1997; Smith et al. 1993). A separation between redistribution (or "hiatus") periods and potential surface saturation periods is introduced. A "hiatus" period starts once the water inflow in the system $q_{e}$ becomes inferior to $K_{s}$ and ponded water is completely infiltrated. It stops when water inflow $q_{e}$ becomes greater than $K_{s}$ (e.g. when saturation can potentially occur). A new front $n+1$ is generated at the end of each hiatus period. While the other fronts are allowed to keep on redistributing, this new front is treated as the saturated profile of the GA equation. Once saturation stops, the saturated profile redistributes along with underlying fronts.

The sole redistribution of the profiles generated with the GA equation (often exhibiting a large extension and thus providing a very rough description of the moisture domain at the end of saturation period) cannot account for a faster water content decrease near soil surface. A specific procedure is thus adopted to allow for a more detailed representation of the uppermost layers of soils and to enable moisture profile inversion under the effect of redistribution and evapotranspiration. 


\section{DERIVATION OF REDISTRIBUTION EQUATIONS}

In the original EBM model an expression of the downward flux $\mathrm{q}_{\mathrm{i}}$ in each uniform $\theta_{i}$ region (e.g. between $Z_{i+1}$ and $Z_{i}$ ) is derived from the continuity equation (Milly 1986):

$$
\frac{\partial \theta_{i}}{\partial t}=-\frac{\partial q_{i}}{\partial z} \Rightarrow \frac{\partial}{\partial z}\left(\frac{\partial \theta_{i}}{\partial t}\right)=-\frac{\partial}{\partial z}\left(\frac{\partial q_{i}}{\partial z}\right)=0
$$

Because the water content $\theta_{i}$ is assumed to be uniform between $Z_{i+1}$ and $Z_{\dot{p}}$ the second derivative of $q_{i}$ with respect to $\mathrm{z}$ is zero, and the following expression is thus adopted for $q_{i}(\mathrm{v})$ :

$$
q_{i}(z)=q_{i n, i}+\left(\frac{z-Z_{i+1}}{L_{i}}\right) \times \Delta q_{i}
$$

Where: $L_{i}=Z_{i}-Z_{i+1}, \Delta q_{i}=$ a function to be determined and $q_{i n, i}=$ water flux entering the uniform $\theta_{i}$ region $=$ $q\left(Z_{i+1}\right)$ with $q_{i n, n}=$ water inflow $q_{e}\left(=\right.$ surface infiltration $f_{\text {s.p }}$ during redistribution) for the uppermost front $(i=n)$ and $q_{i, i, i[;,-1]}=K\left(\theta_{i}\right)$ otherwise. It may immediately be noted that, unless $\Delta q_{i}=0$, a contradiction arises between equations (3) and Darcy's law which predicts a uniform flux over a uniform $\theta$ region. As stated by Milly (1986), this inconsistency however originates from our representation of the moisture profile, which is necessarily unrealistic and should only be interpreted in terms of averaged water contents.

The expression for the remaining term $\Delta q_{i}$ may be obtained from a depth integration of Darcy's law and equation (3) between $Z_{i+1}$ and $Z_{i}$ :

$$
\frac{1}{L_{i}} \int_{Z_{i+1}}^{Z_{i}} q_{i}(z) d z=\frac{1}{L_{i}} \int_{Z_{i+1}}^{Z_{i}}\left(-D(\theta) \frac{\partial \theta}{\partial z}+K(\theta)\right) d z=K\left(\theta_{i}\right)-\frac{1}{L_{i}} \int_{Z_{i+1}}^{Z_{i}} D(\theta) \frac{\partial \theta}{\partial z} d z
$$

Where: $D(\theta)$ is the soil water diffusivity $=K(\theta) \times d \Psi / d \theta\left(\left[\mathrm{L}^{2} \cdot \mathrm{T}^{-1}\right]\right)$ with $\Psi$ the soil matric suction $([\mathrm{L}])$. Again, because the model introduces discontinuities in the moisture profile $\theta(₹)$, hypotheses regarding $D(\theta)$ are needed to carry out the integration of the diffusive term in equation 4 . In the case of the GA model $\left(i=n\right.$ and $\theta_{\mathrm{n}}=\theta_{\mathrm{s}}$ in equation 4), $D(\theta)$ follows a delta-Dirac distribution and the diffusive term in equation (4) can be expressed as a function of the mean diffusivity $\bar{D}$ estimated from sorptivity measurements. $\bar{D}$ may be related to the integral of $D(\theta)$ from $\theta_{s}$ to $\theta_{n-1}$ through a shape factor $\beta \geq 1$ which accounts for the deviation from a sharp wetting front (Stewart et al. 2013; Triadis and Broadbridge 2012; White and Sully 1987). Following a similar approach, the contribution of capillary forces in equation (4) becomes:

$$
-\frac{1}{L_{i}} \int_{Z_{i+1}}^{Z_{i}} D(\theta) \frac{\partial \theta}{\partial z} d z=\frac{\bar{D}}{L_{i}}=\frac{1}{L_{i} \beta} \int_{\theta_{i}}^{\theta_{i+1}} D(\theta) d \theta
$$

Equation (4) may thus be rewritten as follow: 


$$
\frac{1}{L_{i}} \int_{Z_{i+1}}^{Z_{i}} q_{i}(z) d z=K\left(\theta_{i}\right)+K_{s} \frac{G\left(\theta_{i}, \theta_{i-1}\right)}{\beta L_{i}}
$$

Where $G\left(\theta_{i} \theta_{i-1}\right)$ represents the capillary drive between two fronts (Morel-Seytoux et al. 1996; Ogden and Saghafian 1997) ([L]), which can be calculated from soil water retention curve $\Psi(\theta)$ and hydraulic conductivity function $K(\theta)$ :

$$
G\left(\theta_{i}, \theta_{i-1}\right)=\frac{1}{K_{s}} \int_{\theta_{i}}^{\theta_{i+1}} D(\theta) d \theta=\frac{1}{K_{s}} \int_{\theta_{i}}^{\theta_{i+1}} K(\theta) \frac{\partial \psi}{\partial \theta} d \theta
$$

Combination of equation (6) and (7) with an integrate form of (3) therefore yields the following expression for $\Delta q_{i}$

$$
\frac{\Delta q_{i}}{2}=-q_{i n, i}+K\left(\theta_{i}\right)+K_{s} \frac{G\left(\theta_{i}, \theta_{i-1}\right)}{\beta L_{i}}
$$

The net downward flux at the $i^{\text {th }}$ front is partitioned between the elongation $d Z_{i} / d t$ of the wetted profile and the flux $q_{i n,-1}$ across the wetting front supplying the underlying uniform $\theta_{i-1}$ region. An expression of this term can be obtained from equation (3) for $z=Z_{i}$ (Milly 1986):

$$
q_{i}\left(Z_{i}\right)=q_{i n, i}+\Delta q_{i}=\left(\theta_{i}-\theta_{i-1}\right) \frac{d Z_{i}}{d t}+q_{i n, i-1}
$$

The differential equation for the water content $\theta_{i}$ associated with each front can then be expressed from a depth integration of the continuity equation using equation (3):

$$
\frac{1}{L_{i}} \int_{Z_{i+1}}^{Z_{i}} \frac{\partial \theta_{i}}{\partial t} d z=-\frac{1}{L_{i}} \int_{Z_{i+1}}^{Z_{i}} \frac{\partial q_{i}}{\partial z} d z \Rightarrow \frac{d \theta_{i}}{d t}=-\frac{\Delta q_{i}}{L_{i}}
$$

Differential equations associated with $\theta_{i}$ and $Z_{i}$ can respectively be obtained substituting equation (8) in (10) and (9). Given that $q_{i, h}=K\left(\theta_{j}\right)$ for $\left.i<n\right)$, redistribution equations associated with soil fronts $\mathrm{n}-1$ to 2 are thus:

$$
\begin{gathered}
\frac{d \theta_{i}}{d t}=-2 K_{s} \frac{G\left(\theta_{i}, \theta_{i-1}\right)}{\beta L_{i}^{2}}{ }_{i<n} \\
\left(\theta_{i}-\theta_{i-1}\right) \frac{d Z_{i}}{d t}=K\left(\theta_{i}\right)-K\left(\theta_{i-1}\right)+2 K_{s} \frac{G\left(\theta_{i}, \theta_{i-1}\right)}{\beta L_{i}} \quad
\end{gathered}
$$

Despite differences related to the introduction of the capillary drive term, these expressions are equivalent to those of Milly (1986). Similarly, equations associated with the uppermost front $(i=n)$ can be obtained from equation (8) to (10) noting that $q_{i, n, n}=f_{s, p} \neq K\left(\theta_{n}\right)$ and $q_{i, n, n-1}=K\left(\theta_{n-1}\right)$. A modification is introduced to account for the effect of evapotranspiration on the uppermost uniform $\theta$ region. Following the approach of Markar and Mein (1987) redistribution equations can be rewritten as follow for $i=n$ : 


$$
\begin{gathered}
Z_{n} \frac{d \theta_{n}}{d t}=2\left[f_{\text {sup }}-K\left(\theta_{n}\right)-K_{s} \frac{G\left(\theta_{n}, \theta_{n-1}\right)}{\beta Z_{n}}\right]-\operatorname{ET}\left(\theta_{n}\right)_{(i=n)} \\
\left(\theta_{n}-\theta_{n-1}\right) \frac{d Z_{n}}{d t}=2 K\left(\theta_{n}\right)+2 K_{s} \frac{G\left(\theta_{n}, \theta_{n-1}\right)}{\beta Z_{n}}-f_{\text {sup }}-K\left(\theta_{n-1}\right)_{(i=n)}
\end{gathered}
$$

Here the assumption that evapotranspiration preferentially affects the uppermost constant $\theta$ region allows for a relatively simple parameterization, avoiding hypothesis regarding roots distribution.

Here, $E T\left(\theta_{n}\right)$ is computed from the Penman-Monteith potential evapotranspiration $E T_{p}$ using the soil moisture index (Morbidelli et al. 2011):

$$
E T\left(\theta_{n}\right)=\left\{\begin{array}{clc}
E T_{p} & \text { if } & \theta_{n}>\theta_{f c} \\
S M I \times E T_{p} & \text { if } & \theta_{f c} \geq \theta_{n} \geq \theta_{w p} \\
0 & \text { if } & \theta_{w p}>\theta_{n}
\end{array} \quad \text { with } \quad S M I=\frac{\theta_{n}-\theta_{w p}}{\theta_{f c}-\theta_{w p}}\right.
$$

Where $S M I=$ soil moisture index, $\theta_{n}=$ water content associated with the uppermost front, $\theta_{m p}=$ wilting point (bulk water content at -15 bar pressure) and $\theta_{f}=$ field capacity estimated from the hydraulic conductivity function with $K\left(\theta_{f}\right)=0.01 \mathrm{~cm} / \mathrm{d}$.

Finally, redistribution equation associated with the lowermost front $(i=1)$ depends on the boundary condition specified at the end the soil domain. In the original EBM model, a maximum wetting front penetration depth $Z_{\text {max }}$ is introduced to limit the extension of the simulation domain (Milly 1986). Corresponding redistribution equation is however not defined. Here, a "free drainage" boundary condition is adopted at the bottom of the soil profile (the groundwater is assumed to lie far below the domain of interest). When the extension of the lowermost front $Z_{1}$ reaches $Z_{\text {max }}$ equations (12) or (14) no longer holds and $d Z_{1} / d t=0$. The flux across $Z_{\text {max }}$ is therefore set to $q_{i, 0}=K\left(\theta_{1}\right)$ and equations (11) and (13) become:

$$
\begin{aligned}
& L_{1}{\frac{d \theta_{1}}{d t}}_{n>1}=0 \\
& Z_{1}{\frac{d \theta_{1}}{d t}}_{n=1}=f_{\text {sup }}-K\left(\theta_{1}\right)-E T\left(\theta_{1}\right)
\end{aligned}
$$

(Note that $d \theta_{1} / d t=0$ for $n>1$ does not imply that water content remains constant at the bottom of soil domain since overlying fronts move down and progressively reach $Z=Z_{\text {max }}$ In other words, $\theta_{1}(t)$ is a simple step function providing a rough description of moisture content at the bottom of the soil profile)

\section{INFILTRATION EQUATIONS}

As long as $q_{e} \leq K_{s}$, infiltration is not limited by soil moisture conditions and $f_{s p p}=q_{e}$ The GA-based infiltration method is implemented as soon as $q_{e}$ becomes greater than $K_{s}$. Before saturation occurs $f_{s p h}=q_{e}\left(>K_{s}\right)$ and both the penetration depth $Z_{n+1}$ and the water content $\theta_{n+1}$ of the newly formed profile are "undefined" (Ogden and 
Saghafian 1997); I2RS hence simply tracks the cumulative infiltration volume $F_{n+1}$ associated with this fictitious front without affecting a value to $\theta_{n+1}$ and $Z_{n+1}$ until saturation occurs.

Once the soil is saturated, $\theta_{n+1}=\theta_{s}$ and $Z_{n+1}$ may be calculated from the cumulative infiltration volume in the saturated profile $F_{n+1}$. Given the condition $q_{i n, n}=K\left(\theta_{n}\right)$ at the lower end of the saturated profile:

$$
F_{n+1}=\int_{t_{\text {satar }}}^{t}\left[q_{\mathrm{e}}-K\left(\theta_{n}\right)-E T\left(\theta_{n}\right)\right] d t=Z_{n+1} \times\left(\theta_{s}-\theta_{n}\right)
$$

Where $t_{\text {sat }}$ is the time associated with the end of previous hiatus period (i.e. when $q_{e}$ becomes larger than $K_{S}$ ).

The procedure of Corradini et al. (1997) can then be adopted to compute time to ponding $t_{p}$ and cumulative infiltration volume $F_{n+1}\left(t_{p}\right)$, with the following conditions in equation (13): $d \theta_{n+1} / d t=0$ (as $\theta_{n+1}=\theta_{2}$ ) and $E T\left(\theta_{n+1}\right)$ $=0$ (evaporation no longer applies to the soil profile under ponded conditions). Corresponding equation (18) may then be solved for unsteady rainfall intensities by verifying at each simulation time step whether $F_{n+1}\left(t_{p}\right)$ has been reached.

$$
\int_{t_{\text {statt }}}^{t_{p}}\left[q_{\mathrm{e}}-K\left(\theta_{n}\right)-E T\left(\theta_{n}\right)\right] d t=Z_{n+1} \times\left(\theta_{s}-\theta_{n}\right)=\frac{K_{s}}{\beta} \frac{G\left(\theta_{s}, \theta_{n}\right)}{q_{\mathrm{e}}-K_{s}} \times\left(\theta_{s}-\theta_{n}\right)
$$

Once saturation has occurred, equation (13) becomes similar to equation (1) and precisely reverts to the GA formula for $\beta=1$.

$$
f_{\text {sup }}=K_{s}\left[1+\frac{\left(\theta_{s}-\theta_{n}\right) G\left(\theta_{s}, \theta_{n}\right)}{\beta F_{n+1}}\right]
$$

In this study, $\beta$ appears in both redistribution and infiltration equations. This coefficient reflects the deviation from the GA assumption of sharp rectangular moisture profile and theoretically depends on soil type, the magnitude of water fluxes at soil surface and moisture content below the wetting front (Corradini et al. 1997; White and Sully 1987). In the case of the saturated profile, $\beta$ may be expected to range between 1 and $\pi / 2$ but literature results suggest that using $\beta=1.1$ would be a reasonable approximation for most soils (MorelSeytoux et al. 1996; Warrick and Broadbridge 1992; White and Sully 1987). In this study, $\beta$ is thus assumed to be invariant and is set to 1.1. (The relevance of this correction and its implications as compared to the traditional GA assumption $\beta=1$ are discussed later on).

Under ponded conditions surface water elevation $z_{\mathrm{p}}$ is added to the capillary term $G\left(\theta_{s}, \theta_{n}\right) / \beta$ in coherence with equation (1). Equation (20) hence becomes:

$$
f_{\text {sup }}=K_{s}\left[1+\left(\theta_{s}-\theta_{n}\right)\left(\frac{G\left(\theta_{s}, \theta_{n}\right) / \beta+z_{P}}{F_{n+1}}\right)\right]
$$


An analytical expression of the integral term in (7) can be derived from the Brooks and Corey (1964) (BC) equations for $\Psi(\theta)$ and $K(\theta)$. Following the approach of Morel-Seytoux et al. (1996) who formulated an expression of $G$ over the whole capillary pressure range, and introducing the relative water content $\Theta=(\theta-$ $\left.\theta_{\nu}\right) /\left(\theta_{s}-\theta\right)$, equation $(7)$ may be rewritten as:

$$
G\left(\Theta_{i}, \Theta_{i-1}\right)=\Psi_{b} \times \delta_{1}+\frac{\Psi_{b}}{\lambda}\left(\frac{\Theta_{i}^{3+1 / \lambda}-\Theta_{i-1}^{3+1 / \lambda}}{3+1 / \lambda}\right)
$$

Where $\Psi_{b}=$ air entry-pressure $([\mathrm{L}])$ and $\lambda=$ dimensionless pore size distribution index (parameters of the $\mathrm{BC}$ relationship). The use of a Kronecker symbol $\delta_{1}$ in (22) is related to the discontinuity in the water retention curve for $\Theta=1$ (e.g. $\theta=\theta$ ). Here, the limit of $G\left(\theta_{s} \theta_{n-1}\right)$ as $\theta_{n-1}$ approaches $\theta_{s}$ is $\Psi_{b}$ instead of 0 in the original GAR model (Ogden and Saghafian 1997). Equation (22) also exactly reverts to the maximum capillary drive as defined by Morel-Seytoux et al. (1990) for $\theta_{n-1}=\theta_{p}$ (while accounting for the effect of soil moisture conditions on the wetting front potential when $\theta_{n-1}>\theta_{\eta}$ ). If water inflow $q_{e}$ falls below $\mathrm{K}_{\mathrm{s}}$ before surface saturation occurs, water content and penetration depth associated with the uppermost front (which has no physical significance) cannot be evaluated Ogden and Saghafian (1997). In this study, the water volume associated $F_{n+1}$ with this "undefined" front is redistributed over the soil profile assuming a water content increase in underlying $\theta$ regions. The latter is computed as $\left(\theta_{s}-\theta_{n}\right) \times F_{n+1} / F_{n+1}\left(t_{P}\right)$ where $F_{n+1}\left(t_{P}\right)$ represents the theoretical time-to-ponding volume $F_{n+1}\left(t_{p}\right)$ (calculated with an average $q_{e}$ value in the right hand term of equation (19)).

\section{MODEL IMPLEMENTATION}

Redistribution equations (11) to (17) are solved applying semi-implicit Euler method whereas a second order Runge-Kutta method is adopted to compute infiltration during saturation periods. An adaptive step-size control is implemented to solve both infiltration and redistribution equations. Similarly to the work of Struthers et al. (2006), a water content and a penetration depth "tolerance" are introduced to avoid computational errors during the redistribution process. Two profiles $i$ and $i-1$ are thus merged when their water content becomes similar $\left(\left|\theta_{i}-\theta_{i-1}\right|<10^{-4}\right)$ or when a given front overlaps the underlying one $\left(\left|Z_{i}-Z_{i-1}\right|<10^{-1} \mathrm{~mm}\right)$.

The procedure adopted to simulate moisture profile inversion (faster water content decrease near soil surface) period is described hereafter. During hiatus periods, a new fictitious front is generated at each time step near soil surface unless the total number of fronts in the first meter of soil exceeds a given value $n_{\text {smax }}$ The thickness of the newly formed soil layer (denoted as $n+1$ ) is set to a small and arbitrary value $\tau_{\text {sini }}$ and its water content to $\theta_{n}$ Depending on underlying moisture conditions and evapotranspiration fluxes, this thin layer of soil may either be merged at the end of the time step or result in a decrease of $\theta_{n+1}$ below $\theta_{n}$ Here, $n_{\text {smax }}=4$ is found to be reasonable tradeoff between computational effort and model performance (as shown in Table S5). The effect of $z_{\text {sini }}$ on infiltration-rates (Table S6 and S15-16) tends to be negligible unless considering values greater than $15 \mathrm{~cm}$ in which case mode moisture profile inversion can no longer occur. Here $z_{j i n}$ is thus set to $10 \mathrm{~cm}$. 


\section{MODEL EVALUATION}

\section{GENERAL METHODOLOGY}

\section{Testing against the solutions of Richards' equation}

Validation of redistribution models against numerical solutions of Richards' equation has generally been carried out for theoretical case studies consisting in successions of rain pulses (Lai et al. 2015; Ogden and Saghafian 1997). In this paper, a similar approach is first adopted to evaluate the I2RS model under simple hydrological forcing scenarios, for different soil types (cf. Table 1). A more complete evaluation is later conducted for long simulation periods, considering a variety of surface boundary conditions (water inflow and ponding depths) representative of those prevailing in SUDS. The characteristics of these tests are provided in corresponding subsections. (verification tests and long period applications).

\begin{tabular}{clccccccc}
\hline Soil n $^{\circ}$ & Soil type & $\mathrm{K}_{\mathrm{s}}(\mathrm{mm} / \mathrm{h})$ & $\theta_{\mathrm{r}}$ & $\theta_{\mathrm{s}}$ & $\Psi_{\mathrm{b}}(\mathrm{mm})$ & $\lambda$ & $\theta_{\mathrm{wp}}$ & $\theta_{\mathrm{fc}}$ \\
\hline 1 & Sandy Clay & 1.2 & 0.109 & 0.430 & 291.7 & 0.168 & 0.222 & 0.329 \\
2 & Silty Clay Loam & 1.5 & 0.040 & 0.471 & 326.7 & 0.151 & 0.211 & 0.340 \\
3 & Clay Loam & 2.3 & 0.075 & 0.464 & 258.9 & 0.194 & 0.188 & 0.317 \\
4 & Sandy Clay Loam & 4.3 & 0.068 & 0.398 & 280.8 & 0.250 & 0.137 & 0.244 \\
5 & Silt Loam & 6.8 & 0.015 & 0.501 & 207.6 & 0.211 & 0.136 & 0.284 \\
6 & Loam & 13.2 & 0.027 & 0.463 & 111.5 & 0.220 & 0.116 & 0.251 \\
7 & Sandy Loam & 25.9 & 0.041 & 0.453 & 146.6 & 0.322 & 0.085 & 0.201 \\
8 & Loamy Sand & 61.1 & 0.035 & 0.437 & 86.9 & 0.474 & 0.047 & 0.141 \\
\hline
\end{tabular}

Table 1. Hydraulic parameters for selected soil types (Brooks and Corey model from Rawls et al. (1982))

For each test, Richards equation is solved numerically using the HYDRUS-1D software (Šimůnek et al. 2009). The implementation of a free drainage boundary condition in HYDRUS-1D results in convergence difficulties for long-term applications when considering limited soil domain extensions (few meters) due to inconsistence in surface and bottom boundary conditions. The evaluation is thus conducted for a 40m deep soil profile with free drainage condition. Obviously, such a condition is very unlikely to be met in real world applications: this choice is solely justified by the need to avoid numerical problems as the study mostly focuses on infiltration rates and near surface water content. The soil column is discretized into 9001 nodes, with 2000 nodes for $z<2 \mathrm{~m}$. As opposed to the I2RS model, HYDRUSD requires root-depth $Z_{\mathrm{ROOT}}$ and root density to be specified to compute evapotranspiration. A $25 \mathrm{~cm}$ value is first adopted assuming uniform root distribution (the importance of this choice is discussed later on, adding $Z_{\mathrm{ROOT}}$ to the parameters identified for sensitivity tests). Water stress reduction in the root zone is accounted for using the standard Feddes function (Šimůnek et al. 2009). The soil cover fraction used in HYDRUS to partition evaporation and transpiration is set to $85 \%$.

The accuracy of infiltration-rates $f_{\text {sp }}$ predictions is evaluated at a 1 min time step from two performance criteria: a benchmark-based index BE (Schaefli and Gupta 2007) derived from the Nash-Sutcliffe coefficient (NS) and a volumetric efficiency VE (Criss and Winston 2008). 
While the original NS coefficient simply reflects the performance of the model as compared to the prediction associated with the use of mean observed data, BE allows for the introduction of more sophisticated "benchmark models". In this study, a constant rate infiltration model $f_{s u p}=K_{s}$ (referred to as CR) is introduced to compute BE:

$$
B E=1-\frac{\sum_{i=1}^{N}\left(Y_{r e f, i}-Y_{s i m, i}\right)^{2}}{\sum_{i=1}^{N}\left(Y_{r e f, i}-Y_{b e n, i}\right)^{2}}
$$

Where $Y_{b m, i}=$ infiltration-rate value calculated with the CR model, $Y_{n f i \text { i }}=$ infiltration-rate calculated with HYDRUS-1D, $Y_{\text {sim }, i}=$ infiltration-rate predicted by the I2RS model, $i=$ subscript associated with each time-step of the simulation series and $\mathrm{N}=$ length of the time series. As for the NS criterion, $B E$ ranges from $-\infty$ to 1 and $B E>0$ indicates the I2RS model has a larger explanatory power than a simpler constant infiltration model, which neglects the variability of $f_{s p h}(B E=1$ implies perfect fit between reference and simulated time series).

The advantage of $B E$ lies in its ability to express the benefits associated with the representation of the temporal variability of infiltration rates.

This performance metrics is complemented by the more straightforward measure of the deviations in infiltrated volumes (differences between $Y_{r f f i} \times d t$ and $Y_{s i m, i} \times d \AA$ provided by VE which represents "the fraction of water [infiltrated] at a proper time" (Criss and Winston 2008):

$$
V E=1-\frac{\sum_{i=1}^{N}\left|Y_{r e f, i}-Y_{\text {sim }, i}\right|}{\sum_{i=1}^{N} Y_{r e f, i}}
$$

The performance for water content predictions is evaluated from the mean absolute percentage error (MAPE) computed for both (1) the water content at the soil surface $\theta_{T O P}$ and (2) the average water content associated with the first $25 \mathrm{~cm}$ of soil $\theta_{250 \mathrm{ir}}$

$$
M A P E=\frac{1}{N} \sum_{i=1}^{N}\left|\frac{\theta_{r e f, i}-\theta_{\text {sim }, i}}{\theta_{r e f, i}}\right|
$$

Where: $\theta_{n f i}=$ water content value $\left(\theta_{\text {TOP }}\right.$ or $\left.\theta_{25 m n}\right)$ computed with HYDRUS-1D; $\theta_{\text {sim }, i}=$ water content value simulated by the I2RS model.

For both surface and average water contents, coefficient of determination $R^{2}$ is additionally calculated so as to verify that the temporal trends simulated by the infiltration-redistribution model are consistent with the HYDRUS-1D solution of Richards' equation. 


\section{Comparison to the results produced by simpler models}

Infiltration rates simulated with the I2RS model for long period applications are compared to those computed from two basic modeling schemes (in addition to the CR benchmark model). The first one consists in the association of the GA equation with a rudimentary redistribution model, where the soil domain is represented as a 2-m deep homogeneous water content reservoir drained at $K(\theta)$ and affected by evapotranspiration. In this case, water content variations can be described by equation (17). This approach, similar to the one adopted in EPA's SWMM for rain garden modeling (Rossman 2010b), is later denoted as GA-RR (Rudimentary Redistribution).

The second option, referred to as GA- $\theta_{0}$, is based on the traditional GA scheme, assuming that surface water content immediately switches to a constant value $\theta_{0}$ when saturation stops (neither redistribution nor evapotranspiration process are represented). Here, $\theta_{0}$ is alternatively set to field capacity $\theta_{F C}$ and to the initial water content $\theta_{\mathrm{OPT}}$ resulting in the best fit to HYDRUS-1D.

\section{VERIFICATION TESTS}

\section{Tests description}

The initial verification is performed for the 8 USDA soil classes for which four successive rainfall pulses (cf. table 2) are applied to soils initially at field capacity, assuming that rainfall excess immediately turns into runoff. Rainfall intensities are adjusted to cause saturation after $15 \mathrm{~min}$ and thus deliberately set very high for some soil classes (such inflow-rates nevertheless remain plausible in the case of stormwater management practices which may receive very large amounts of water). It may be noted that saturated hydraulic conductivity values associated with some soil classes may be regarded as low for conventional stormwater infiltration practices; these configurations are nonetheless considered here as the infiltration of a limited fraction of the volume collected by a facility may still provide some runoff control.

\begin{tabular}{|c|c|c|c|c|c|c|c|c|c|}
\hline \multirow{2}{*}{$\begin{array}{l}\text { Soil } \\
n^{\circ}\end{array}$} & \multirow{2}{*}{$\begin{array}{l}\text { Adjusted } \\
\text { intensity }\end{array}$} & \multicolumn{2}{|c|}{ Pulse $n^{\circ} 1$} & \multicolumn{2}{|c|}{ Pulse $n^{\circ} 2$} & \multicolumn{2}{|c|}{ Pulse $n^{\circ} 3$} & \multicolumn{2}{|c|}{ Pulse $n^{\circ} 4$} \\
\hline & & Date & Duration & Date & Duration & Date & Duration & Date & Duration \\
\hline 1 & $14.5 \mathrm{~mm} / \mathrm{h}$ & \multirow{8}{*}{$\mathrm{T}=0 \mathrm{~h}$} & \multirow{8}{*}{$1 \mathrm{~h}$} & \multirow{8}{*}{$\mathrm{T}=6 \mathrm{~h}$} & \multirow{8}{*}{$30 \mathrm{~min}$} & \multirow{8}{*}{$\mathrm{T}=7 \mathrm{~h}$} & \multirow{8}{*}{$30 \mathrm{~min}$} & \multirow{8}{*}{$\mathrm{T}=9 \mathrm{~h}$} & \multirow{8}{*}{$1 \mathrm{~h}$} \\
\hline 2 & $19.6 \mathrm{~mm} / \mathrm{h}$ & & & & & & & & \\
\hline 3 & $22.8 \mathrm{~mm} / \mathrm{h}$ & & & & & & & & \\
\hline 4 & $33.3 \mathrm{~mm} / \mathrm{h}$ & & & & & & & & \\
\hline 5 & $43.9 \mathrm{~mm} / \mathrm{h}$ & & & & & & & & \\
\hline 6 & $47.8 \mathrm{~mm} / \mathrm{h}$ & & & & & & & & \\
\hline 7 & $83.3 \mathrm{~mm} / \mathrm{h}$ & & & & & & & & \\
\hline 8 & $121.4 \mathrm{~mm} / \mathrm{h}$ & & & & & & & & \\
\hline
\end{tabular}

Table 2. Theoretical rainfall sequences used for model verification

The effect of initial moisture conditions and rainfall intensities on model performance was addressed through simple sensitivity tests conducted for soil $\mathrm{n}^{\circ} 5$. Both parameters were found to have a limited incidence on model performance. Detailed results are provided as supplementary data (Table S2 to S3). 


\section{Results}

The accuracy of the I2RS model for the prediction of infiltration rates is generally very good (cf. figure 3 and S1-8), with BE and $V E$ values systematically greater than 0.99 (detailed results can be found in Table S1). The introduction of $\beta$ in equations (18) to account for the deviation from a rectangular moisture profile (GA assumption) is found to improve model performance (cf. Table S4): the error associated with infiltration volumes for the different rainfall pulses indeed ranges from $-1.4 \%$ to $2.2 \%$ (with an average over the 4 rain pulses of $0.4 \%$ ) for $\beta=1.1$ vs. $-2.4 \%$ to $4.8 \%$ (with an average of $3.1 \%$ ) for $\beta=1$. This overestimation of infiltration rates observed for $\beta=1$ is consistent with several findings regarding the GA equation(Barry et al. 1993; Freyberg et al. 1980; Triadis and Broadbridge 2012). As opposed to previous GAR-models (Ogden and Saghafian 1997), deviations associated with cumulative infiltration volumes here do not significantly increase after successive redistribution cycles.
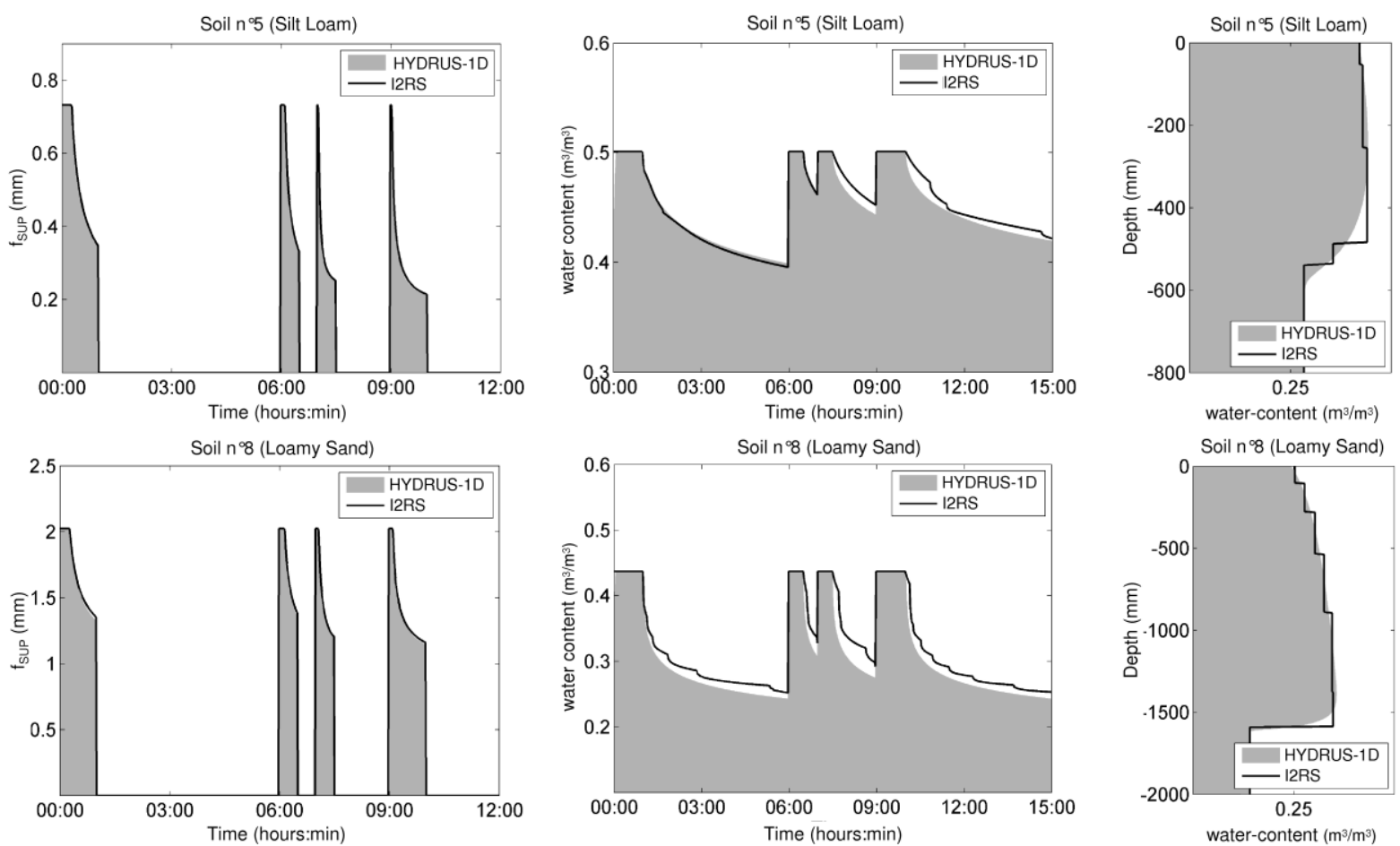

Figure 3. Simulation results for four successive rain pulses (infiltration-rates $f$, surface water content and moisture profile at the end of rainfall sequence) for two soil types

Although systematically overestimated for coarsest soils, surface water content $\theta_{\mathrm{TOP}}$ predictions remain very satisfactory with MAPE value ranging from $0.6 \%$ for soil $n^{\circ} 1$ to $4.8 \%$ for soil $n^{\circ} 8$ whereas $R^{2}$ systematically exceeds 0.96. As for the GAR model (Ogden and Saghafian 1997), the aforementioned overestimation of $\theta_{T O P}$ is mainly related to the distortion of the actual wetting profile near soil surface during redistribution. These errors however remain very acceptable due to the ability of the I2RS model to simulate moisture profile inversion (as shown in figure 3). Water content predictions tend to become even more consistent when considering the average water content over the first $25 \mathrm{~cm}$ of soil, with MAPE values systematically lower than 
$1.0 \%$ and $\mathrm{R}^{2}$ greater than 0.99 for the 8 soil classes (deviations were additionally found to decrease for extensions larger than $25 \mathrm{~cm}$ as shown in Table S19)

\section{LONG PERIOD SIMULATIONS}

\section{Tests description}

Long-term simulations are conducted for 7 soil types under realistic hydrologic conditions (soil $n^{\circ} 8$ could not be considered here due to convergence problems in the resolution of Richards' equation). For each scenario, surface boundary conditions are adjusted to simulate a simple storage unit collecting runoff originating from urban surfaces. Because SUDS with more pervious soils can accommodate larger runoff volumes, a ratio $b$ between the surface area of the facility and the drainage area is introduced for the definition of stormwater infiltration scenarios. Maximum ponding depth over soil surface $h_{M A X}$ is initially set to $20 \mathrm{~cm}$ (a realistic value for SUDS as ponding depth is often limited for better site integration). The area ratio b associated with each soil type (table 3) is adjusted to result in an approximately $80 \%$ annual runoff volume reduction, which is a relatively usual target in the context of on-site stormwater management (Sage et al. 2015). These simulations clearly do not cover the diversity of possible SUDS design; they rather provide realistic surface boundary conditions so as to evaluate the ability of the I2RS model to simulate infiltration-rates and near surface water content under such conditions.

Simulations are conducted for a 1 year period (June 2007 to June 2008) using rainfall records (5-min time-step) collected on different stations of the Hauts-de-Seine department near Paris (additional details can be found in Sage (2016) p. 330). The cumulative rainfall volume for that period $(613 \mathrm{~mm})$ is close to the average annual value observed in Paris region. Runoff time-series are under the assumption that rainfall is immediately and totally converted into runoff (e.g. no losses and instantaneous transfer on drainage area). Evapotranspiration is computed from daily Penman-Monteith potential evapotranspiration values $E T_{R E F}$ calculated with the French meteorological service method (Choisnel 1988) in the Hauts-de-Seine department. Potential evapotranspiration $E T_{\mathrm{P}}$ rates are adjusted from $E T_{\mathrm{REF}}$ using a simple crop coefficient $\mathrm{K}_{\mathrm{CROP}}\left(E T_{P}=K_{\mathrm{CROP}} \times E T_{\mathrm{REF}}\right)$ set to 0.75 (a value consistent with those reported in Romero and Dukes (2015) for turfgrass).

A simple "one-factor-at-a-time" sensitivity analysis was performed for soil $\mathrm{n}^{\circ} 1$ and $\mathrm{n}^{\circ} 5$ to assess the effect of $K_{\text {CROP }}$ and $Z_{\text {ROOT }}$ (additional root depth parameter introduced for the resolution of Richards' equation) and of the design parameters $b$ and $\mathrm{h}_{\mathrm{MAX}}$ on the performance of the I2RS model. Overall, the accuracy of infiltration rates prediction was not significantly affected by $b$ (infiltration to drainage area ratio) and $b_{M A X}$ (maximum ponding depth). Results associated with these two parameters are provided as supplementary data (Table S7 and S8). The effect of evapotranspiration related parameters is presented later on. Finally, the benefits of an accurate description of near surface water content (in relation with the introduction of an evapotranspiration term in redistribution equations and the procedure implemented to simulate moisture profile inversion) are briefly illustrated by disabling evapotranspiration and setting discretization parameter $n_{\text {smax }}$ to 0 in the I2RS model. 


\section{Overall-model performance}

As indicated in table 3, the I2RS model provides very satisfactory estimates of infiltration rates over the 1year simulation period, resulting in high efficiency coefficient values for all soil types. Comparison to verification results evidences a minor decrease of the two efficiency coefficients $B E$ and $V E$. This slightly lower model performance believably results from a less accurate estimation of surface and average water contents originating from the multiplication of redistribution cycles as well as the introduction of the evapotranspiration term. Water content predictions nonetheless remain very satisfactory for both $\theta_{\text {TOP }}$ and $\theta_{25 \mathrm{~cm}}$

\begin{tabular}{|c|c|c|c|c|c|c|c|}
\hline \multirow[b]{2}{*}{ Soil $n^{\circ}$} & \multirow[b]{2}{*}{ b (\%) } & \multicolumn{2}{|c|}{$f_{\text {sup }}$} & \multicolumn{2}{|c|}{$\theta_{\mathrm{TOP}}$} & \multicolumn{2}{|c|}{$\theta_{25-\mathrm{cm}}$} \\
\hline & & $\mathrm{BE}$ & VE & MAPE & $\mathrm{R}^{2}$ & MAPE & $\mathrm{R}^{2}$ \\
\hline 1 & 8.0 & 0.97 & 0.97 & $0.9 \%$ & 0.98 & $0.6 \%$ & 0.99 \\
\hline 2 & 7.0 & 0.97 & 0.97 & $0.9 \%$ & 0.98 & $0.9 \%$ & 0.98 \\
\hline 3 & 6.0 & 0.98 & 0.98 & $1.4 \%$ & 0.98 & $0.9 \%$ & 0.99 \\
\hline 4 & 4.5 & 0.98 & 0.97 & $1.3 \%$ & 0.99 & $0.9 \%$ & 0.99 \\
\hline 5 & 4.0 & 0.98 & 0.97 & $1.9 \%$ & 0.98 & $1.2 \%$ & 0.99 \\
\hline 6 & 3.0 & 0.97 & 0.97 & $3.0 \%$ & 0.97 & $1.7 \%$ & 0.98 \\
\hline 7 & 2.5 & 0.97 & 0.97 & $3.3 \%$ & 0.96 & $2.0 \%$ & 0.98 \\
\hline
\end{tabular}

Table 3. Evaluation results for long-period applications

Detailed examination of the residuals between the outputs of I2RS and HYDRUS-1D (figure 4 and S9-15) indicates that infiltration-rates tend to be underestimated at early stages of infiltration (when $f_{\text {sup }}$ largely exceeds $K_{S}$ ). As a consequence, the time required to infiltrate the water stored at soil surface is conversely slightly overestimated; negative residuals are therefore observed where HYDRUS-1D predicts that surface saturation has already stopped $\left(f_{\text {sup }}=0\right)$.
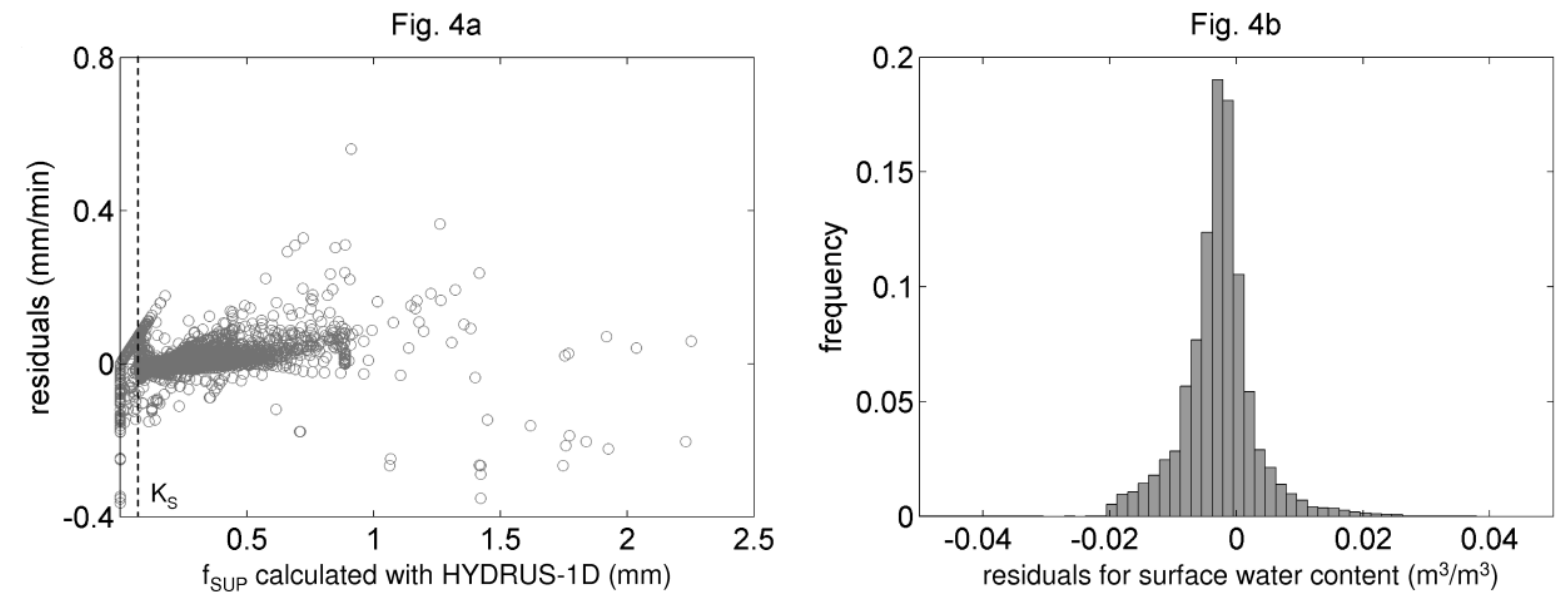

Figure 4. Analysis of residuals for soil $\mathrm{n}^{\circ} 4$ (sandy clay loam) for the 1-year simulation (Difference between the values obtained with HYDRUS-1D and those simulated with I2RS) - 4a: Residuals (infiltration-rates) as a function of infiltration-rates as computed by HYDRUS-1D, 4b: distribution of residuals for surface water content predictions (during redistribution periods) 
This observation is consistent with the slight overestimation of surface water content shown in figure $4 \mathrm{~b}$ (negative residuals). The line "residuals $=f_{s p}$ " in figure $4 a$ however clearly suggest that this underestimation of infiltration rates is not systematic, as such pattern implies that HYDRUS-1D computes non-zero infiltration fluxes whereas ponding already stopped in the I2RS model.

These errors nevertheless remain very limited and the model generally provides very satisfactory predictions of both infiltration rate and water contents. The ability of the I2RS model to simulate the evolution of soil moisture profile is illustrated in figure 5 :
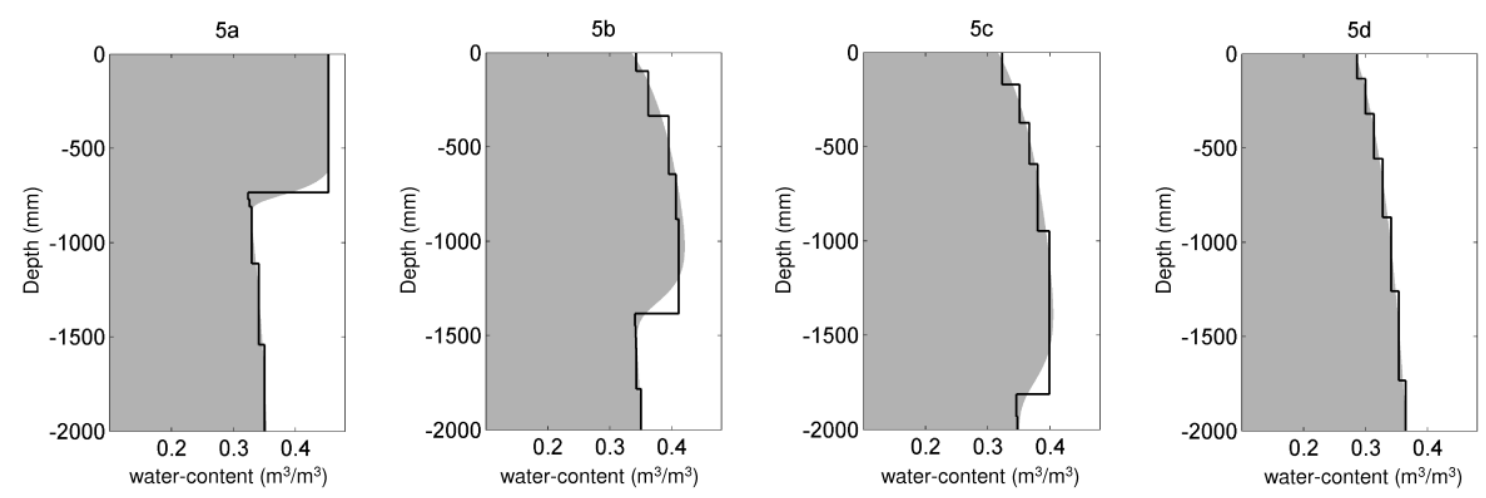

Figure 5. Water content profile simulated for an infiltration event (after 10 days of simulation) and during subsequent redistribution period for soil $n^{\circ} 7$ (sandy loam). Grey shaded area: Hydrus-1D, solid black line:

I2RS model - 5a: end of the infiltration event $(t=10$ days); $5 \mathrm{~b}$ : after $3 \mathrm{~h}$; $5 \mathrm{c}$ : after $6 \mathrm{~h}$; $5 \mathrm{~d}$ : end of the redistribution period, after approximately 1 day

\section{Comparison with simpler modeling approaches}

Comparison between the different modeling options (Table 4) primarily indicates that the I2RS model systematically outperforms simpler GA approaches for the prediction of infiltration fluxes. The benefits associated with a detailed representation of soil moisture content variations are particularly visible for moderate to low permeability soils ( $\mathrm{n}^{\circ} 1$ to 5 ). Although the adoption of a simpler method produces a less important decrease in $B E$ and $V E$ in the case of coarser soils, differences from the I2RS model remain substantial.

The association of the GA equation with a rudimentary redistribution model, assuming uniform water content over the soil profile and gravity drainage (GA-RR), seems to provide relatively solid estimates of $f_{\text {SUP }}$ Similarly, efficiency criteria computed for the simple GA approach reveals that neglecting the redistribution process may as well be acceptable, as long as the value of the fixed initial water content $\theta_{0}$ is appropriately selected (GA- $\theta_{\text {OPT }}$ in Table 4). However, determination of this appropriate $\theta_{0}$ value may be somewhat difficult (as the later obviously depends on the hydrological behavior of the facility) and a poor choice regarding the latter could strongly affect the accuracy of infiltration rate predictions (cf. Figure S16-17). (As shown in Figure S16, a $10 \%$ deviation from $\theta_{\text {OPT }}$ for instance results in an $80 \%$ and $30 \%$ decrease of $\mathrm{BE}$ and VE for soil $\mathrm{n}^{\circ} 2$ ). 


\begin{tabular}{ccccccccccc}
\hline Model & \multicolumn{2}{c}{ I2RS } & \multicolumn{2}{c}{ GA-RR } & \multicolumn{2}{c}{ GA- $\theta_{\text {OPT }}$} & \multicolumn{2}{c}{ GA- $\theta_{\text {FC }}$} & \multicolumn{2}{c}{ CR } \\
Soil $n^{\circ}$ & BE & VE & BE & VE & BE & VE & BE & VE & BE & VE \\
1 & 0.97 & 0.97 & 0.79 & 0.88 & 0.76 & 0.89 & -0.53 & 0.52 & $/$ & 0.64 \\
2 & 0.97 & 0.97 & 0.77 & 0.84 & 0.75 & 0.84 & -0.33 & 0.44 & $/$ & 0.51 \\
3 & 0.98 & 0.98 & 0.78 & 0.84 & 0.80 & 0.86 & -0.02 & 0.48 & $/$ & 0.50 \\
4 & 0.98 & 0.97 & 0.80 & 0.84 & 0.81 & 0.82 & 0.28 & 0.54 & $/$ & 0.43 \\
5 & 0.98 & 0.97 & 0.83 & 0.85 & 0.85 & 0.86 & 0.27 & 0.55 & $/$ & 0.38 \\
6 & 0.97 & 0.97 & 0.82 & 0.89 & 0.85 & 0.90 & 0.39 & 0.70 & $/$ & 0.55 \\
7 & 0.97 & 0.97 & 0.86 & 0.91 & 0.87 & 0.90 & 0.45 & 0.73 & $/$ & 0.53 \\
\hline
\end{tabular}

Table 4. Comparison of the I2RS model with simpler modeling approaches (GA-RR: GA equation and rudimentary redistribution scheme; GA- $\theta_{\mathrm{OPT}}$ : GA with constant initial moisture content adjusted to produce the best fit to HYDRUS-1D, GA- $\theta_{\mathrm{FC}}$ : GA with constant initial moisture set to field capacity; CR: constant rate model)

The distribution of the residuals associated with the different modeling approaches for soil $\mathrm{n}^{\circ} 3$ and 6 is presented in figure 6. Comparison between the two soils first indicates that the frequency and the magnitude of model errors, relatively to the saturated hydraulic conductivity, tend to be more important in the case of soil $\mathrm{n}^{\circ} 6$. Because the variability of infiltration rates is also larger in this case $\left(\sigma=0.9 \times K_{S}\right.$ vs. $\left.\sigma=0.67 \times K_{S}\right)$, as a result of higher suction head in the GA equation value, the effect on $B E$ and $V E$ however remains moderate (cf. Table 4).
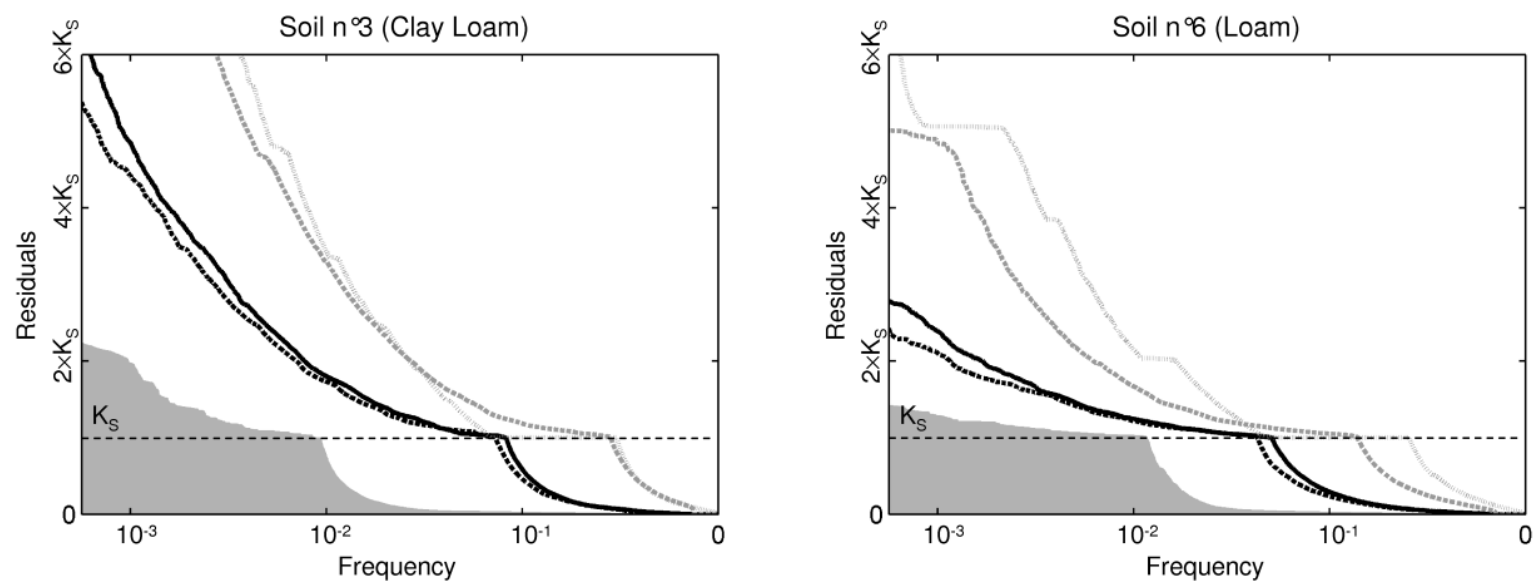

Figure 6. Distribution of absolute residuals (difference between the values obtained with HYDRUS-1D and those simulated with the different modeling options, excluding observations for which all models produce

$\left.\mathrm{f}_{\text {sup }}=0\right)$ for the different modeling options for soil $n^{\circ} 3$ (clay loam) and soil $n^{\circ} 6$ (loam). Grey shaded area:I2RS model; Plain black line: GA-RR, Black dashed-line; GA-OPT; Grey dashed line: GA-FC; Lightgrey dotted line: the constant rate model.

Both graphs confirm the poor performance of the constant rate infiltration model and the simple GA approach for $\theta_{0}=\theta_{\mathrm{FC}}$, with significantly higher deviations for a similar frequency. Although deviations from the I2RS model tend to be more limited in the case of the GA-RR and the GA- $\theta_{\text {OPT }}$ methods, distributions nevertheless corroborates the results presented in table 4. In the case of the GA-RR approach, the frequency associated with errors greater than $0.5 \times K_{S}$ is for instance more than 8 times as high as for the more sophisticated I2RS model in the case of soil $\mathrm{n}^{\circ} 3$ and about 5 times as high for soil $\mathrm{n}^{\circ} 5$. Although relatively 
infrequent (about 10\% of observations), these errors remain significant. These $10 \%$ represent approximately represent 16 days of simulation and a cumulative error of $2100 \mathrm{~mm}$ for soil $\mathrm{n}^{\circ} 3$ and 6 days with $1100 \mathrm{~mm}$ error for soil $n^{\circ} 5$.

\section{Effect of evapotranspiration related parameters}

The variations of $B E$ and $V E$ associated with changes in evapotranspiration parameters $K_{C R O P}$ and $Z_{\text {ROOT }}$ are presented in figure 7 (further details can be found in Table S9-12). Note that $Z_{\mathrm{ROOT}}$ is not a parameter of the I2RS model but rather an input to be specified in HYDRUS-1D that may affect reference infiltration and water-content time series. The sensitivity analysis primarily indicates that the two soils tested here do not exhibit the same behavior. While variations in model performance remain limited for the most pervious soil $\left(\mathrm{n}^{\circ} 5\right)$, the effect of $K_{C R O P}$ and $Z_{\text {ROOT }}$ tends to be more important in the case of the less permeable one ( $\left.\mathrm{n}^{\circ} 1\right)$, for which evapotranspiration believably become substantial as compared to downward redistribution fluxes.
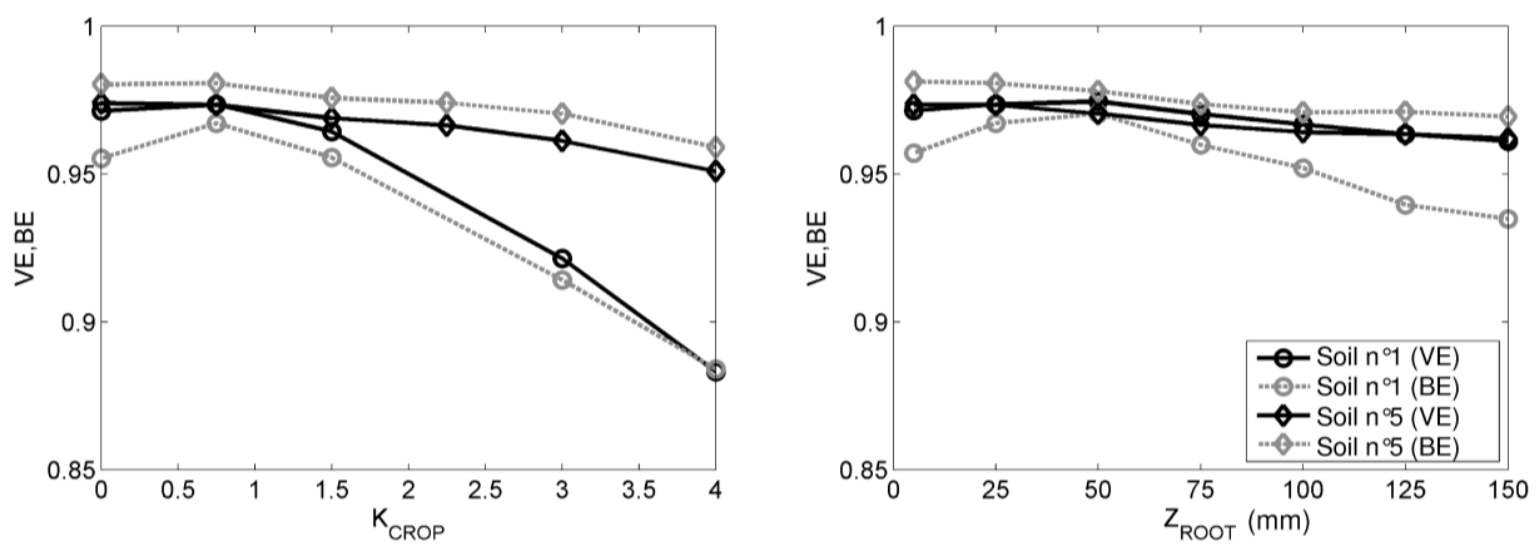

Figure 7. Incidence of evapotranspiration parameters $\mathrm{K}_{\mathrm{CROP}}$ and $\mathrm{Z}_{\mathrm{ROOT}}$ on the accuracy of infiltration rates predictions for soiln ${ }^{\circ} 5$ (silt loam) and $\mathrm{n}^{\circ} 1$ (sandy clay)

Expectedly, the accuracy of infiltration-rate predictions gradually deteriorates when large $Z_{\mathrm{ROOT}}$ values are adopted, as the assumption that evapotranspiration preferentially affects the uppermost layer of soil (adopted in the I2RS model) becomes less realistic. Although, model performance remains unaffected for usual root depth values $(<50 \mathrm{~cm})$, the introduction of root depth parameter in the I2RS models may hence be considered for some applications.

Similarly, the augmentation of evapotranspiration fluxes causes a noticeable drop of $V E$ and $B E$ for soil $n^{\circ} 1$; deviations from the aforementioned hypothesis regarding the application of evapotranspiration in the IR2S model are here exacerbated when $K_{C R O P}$ increases. The application of higher $K_{C R O P}$ values as well results in a more pronounced inversion of the soil moisture profile that cannot completely be captured by the I2RS model (for soil $\mathrm{n}^{\circ} 1$ and $\mathrm{n}^{\circ} 5$, errors associated with $\theta_{\text {TOP }}$ hence reach $2.9 \%$ and $5.5 \%$ for $K_{\text {CROP }}=4$ vs. $0.9 \%$ and $1.9 \%$ for the reference configuration). The upper range of $K_{C R O P}$ values shown in figure 7 are however not realistic, unless considering very specific plant species (or very high atmospheric water demand). Hence, 
if the model may not be suitable for the simulation of low permeability soils under such conditions, its performance clearly remains satisfactory for SUDS modeling under temperate climates.

\section{Importance of near surface water-content description}

Neglecting evapotranspiration in the redistribution process produces contrasted effects depending on soil type. For $K_{a v p}=0.75$ in HYDRUS-1D, $V E$ and $B E$ respectively drop to 0.90 and 0.57 for soil $\mathrm{n}^{\circ} 1$ whereas the effect is mostly negligible for soil $\mathrm{n}^{\circ} 5$ (as shown in table S17, a more noticeable effect is observed for $K_{\text {app }}=3$ ). On the contrary, disabling the procedure implemented to simulate the fast decrease of near surface water content in the I2RS model systematically deteriorates model performance, with $V E$ and $B E$ value ranging from 0.78 to 0.88 and 0.48 to 0.82 (see table S18). Results therefore indicate that (1) accounting for evapotranspiration may often not be needed to accurately replicate infiltration-rates (although it remains necessary to properly describe water balance) whereas (2) simulating moisture profile inversions (mainly associated with gravity and capillary forces) can markedly improve model predictions.

\section{COMPUTATIONAL EFFICIENCY}

Conducting a proper evaluation of the numerical efficiency of the I2RS model as compared to HYDRUS$1 \mathrm{D}$ is a difficult exercise given the differences between the two codes. First, languages are not equivalent: HYDRUS-1D is a compiled FORTRAN program whereas I2RS has yet only been implemented in an interpreted and higher-level language (Matlab). Optimization of the I2RS model has not yet been conducted and the later still incorporates a relatively strict time-step control (for a given time step, simulations are systematically performed for at least $d t$ and $d t / 2$ and an exponential time-step refinement is used when tolerance regarding water content, water balance and infiltration rates are not satisfied). Secondly, the efficiency of HYDRUS-1D significantly depends on temporal and spatial discretization that should in principle be adapted on a case-by-case basis.

Here, the convergence issues encountered with HYDRUS-1D for the Brooks-Corey model resulted in very long simulation times (typically, several hours for a one-year period as a result of a particularly fine time and spatial discretization). Because these difficulties clearly originate from the large air-entry value of the BrooksCorey model, a comparison is here performed using the more stable Van-Genuchten model in HYDRUS1D. Simulations are conducted for a one year rainfall period (5-min time step in both HYDRUS-1D and I2RS) and a 2-m deep soil profile. The latter is described by 151 nodes mesh $(1 \mathrm{~cm}$ near soil surface to $3 \mathrm{~cm}$ at the bottom of the profile) in HYDRUS-1D. Iteration criteria are set to their default value $\left(10^{-3} \mathrm{~m}^{3} / \mathrm{m}^{3}\right.$ water content and $1 \mathrm{~cm}$ pressure head tolerance). Van Genuchten parameters are those provided in HYDRUS-1D except $K_{S}$ which is set in accordance with table 1 . The results of the comparison are presented in table 5 and S20. 


\begin{tabular}{|c|c|c|c|c|c|c|c|c|c|}
\hline \multirow[b]{2}{*}{ Soil $n^{\circ}$} & \multirow[b]{2}{*}{$\mathrm{b}(\%)$} & \multicolumn{4}{|c|}{ HYDRUS-1D } & \multicolumn{4}{|c|}{ I2RS } \\
\hline & & ${ }^{1}$ Time (s) & Iterations & ${ }^{2} \mathrm{~N}_{\text {nodes }}$ & ${ }^{3} \varepsilon_{\mathrm{BAL}}(\%)$ & ${ }^{1}$ Time (s) & Iterations & ${ }^{4} \mathrm{~N}_{\text {front }}$ & ${ }^{1} \varepsilon_{\mathrm{BAL}}(\%)$ \\
\hline 1 & 8 & 43 & $3.6 \times 10^{5}$ & 151 & 0.3 & 23 & $2.6 \times 10^{5}$ & 6.0 & 0.0 \\
\hline 2 & 7 & 91 & $8.8 \times 10^{5}$ & 151 & 0.1 & 25 & $3.3 \times 10^{5}$ & 6.7 & 0.0 \\
\hline 3 & 6 & 129 & $1.2 \times 10^{6}$ & 151 & 0.1 & 28 & $3.2 \times 10^{5}$ & 7.4 & 0.2 \\
\hline 4 & 4.5 & 75 & $6.1 \times 10^{5}$ & 151 & 0.1 & 33 & $3.7 \times 10^{5}$ & 8.4 & 0.1 \\
\hline 5 & 4 & 253 & $2.6 \times 10^{6}$ & 151 & 0.6 & 33 & $3.3 \times 10^{5}$ & 8.9 & 0.5 \\
\hline 6 & 3 & 391 & $4.8 \times 10^{6}$ & 151 & 0.1 & 33 & $3.3 \times 10^{5}$ & 8.5 & 0.4 \\
\hline 7 & 2.5 & 217 & $2.2 \times 10^{6}$ & 151 & 0.3 & 41 & $4.4 \times 10^{5}$ & 8.9 & 0.5 \\
\hline
\end{tabular}

Table 5. Computational efficiency of the I2RS model as compared to HYDRUS-1D ('1for a $3.6 \mathrm{GHz}$ Xeon processor; ${ }^{2}$ number of nodes in HYDRUS-1D; ${ }^{3}$ water balance error as defined in Šimunㅡ른 ․ㅡ a al. (2009); ${ }^{4}$ average number of front during the simulation)

Simulation times of the I2RS model are at least equivalent to those of HYDRUS-1D, and significantly lower for most test cases. Comparison between iteration requirements, up to one order of magnitude larger in the case of HYDRUS-1D, suggests that the performance of the I2RS model could probably be further improved. The relevance of the I2RS model is also illustrated by the average number of homogeneous water content profiles $N_{\text {frum }}$, that can be interpreted in terms of vertical discretization (much coarser than the one typically used for the resolution of Richards equation).

\section{APPLICATION TO MULTIPLE STORMWATER INFILTRATION SCENARIOS}

\section{Methodology}

The I2RS model is implemented to simulate 5000 stormwater infiltration scenarios, generated randomly for the 8 soil classes presented in table 1 with ponding depth $h_{M A X}$ ranging from 1 to $40 \mathrm{~cm}$ and area ratio b between 1 and $10 \%$. As for I2RS evaluation, the facility is assumed to behave as a simple storage unit providing volume reduction through infiltration and evapotranspiration. Once again, the diversity of SUDS system is only addressed in terms of surface boundary conditions and soil properties. As for the evaluation the computational efficiency, the extension of the soil domain $Z_{\text {max }}$ is limited to $2 \mathrm{~m}$.

A significantly longer simulation period (15 years, recorded at the same stations as for model evaluation) is here considered to derive a variety of metrics related to the performance of the different stormwater system designs:

- The overall volume reduction efficiency $E_{\text {TOT }}(\%)$ computed as $1-Q_{\text {TOT }} / P_{\text {TOT }}$ where $Q_{\text {TOT }}$ is the total overflow volume and $P_{\text {TOT }}$ the cumulative rainfall volume entering the facility

- The return period $T_{\text {OUT }}$ associated with the exceedance of the storage capacity (i.e. stormwater discharge)

- The volume reduction efficiency computed for different rainfall return periods ( $T=3$ months, 6 months and 1 year) as $E_{T}=1-Q_{T} / P_{T}$ where $Q_{T}$ is the discharge volume (expressed as a runoff depth) and $P_{T}$ the rainfall depth associated with $T$ 
These indicators are compared to those obtained for simpler modeling approaches to assess the importance of a detailed description of both the inter- and the intra-event variability of infiltration fluxes for the modeling of SUDS. Simplified models selected here include those presented in previous section (GA-RR and GA- $\theta_{0}$ with $\theta_{0}=\theta_{\mathrm{FC}}$ ) as well as the constant-rate $(\mathrm{CR})$ infiltration model $f_{\text {sup }}=K_{s}$. A detailed examination of the results is then performed to understand under which circumstances larger errors are likely to occur.

\section{Results}

Mean and median volume reduction efficiency obtained from this sample with the I2RS model are $75 \%$ and $82 \%$. Percent deviations in the value of the different efficiency indicators (as compared to the I2RS model) are presented in figure 8.
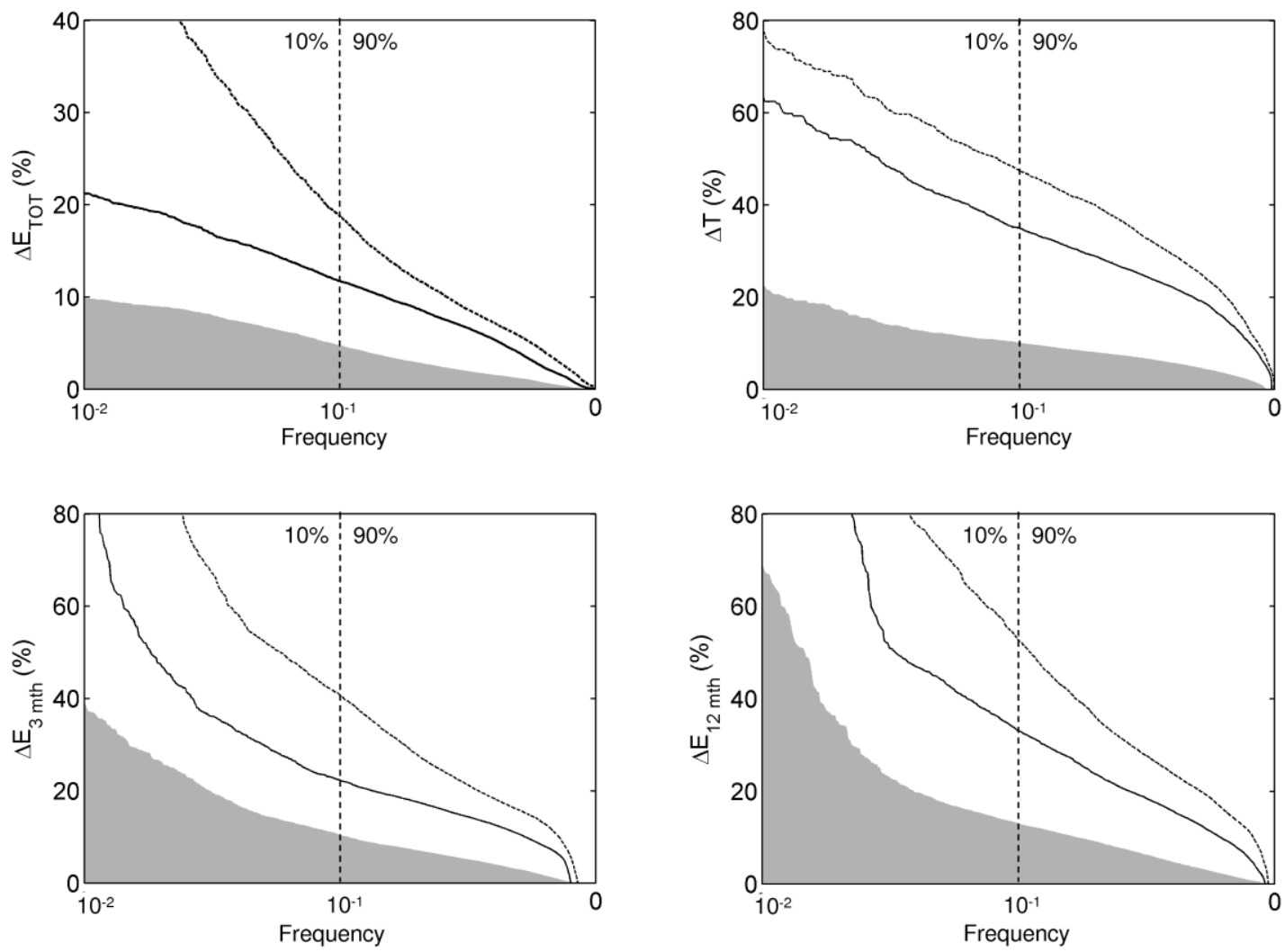

Figure 8. Distribution of absolute percentage deviations from the I2RS model for different model outputs ( $\mathrm{E}_{\text {TOT }}$ is total volume reduction efficiency, $\mathrm{T}$ the return period associated with non-zero discharge and $\mathrm{E}$-3mths and $\mathrm{E}-12 \mathrm{mths}$ volume reduction efficiencies computed for the 6 and 12 month retun period ; $\Delta \mathrm{E}$-6mths is not shown here). Grey shaded area: GA-RR model; Solid black line: GA- $\theta_{\mathrm{FC}}$; Black dashed-line: CR-model

Total volume reduction efficiencies $E_{T O T}$ simulated with the rudimentary redistribution scheme (GA-RR) generally remain close to those computed with the I2RS model (with percentage deviations smaller than $5 \%$ for approximately $90 \%$ of the configurations tested here). Departures from these values tends to be much more important for the fixed initial water content approach $\left(\mathrm{GA}-\theta_{\mathrm{FC}}\right)$ and the constant-rate model 
(CR), with relative errors larger than $35 \%$ and $45 \%$ for $10 \%$ of the simulations, respectively. Regarding the return period $T_{\text {OUT }}$ associated with the exceedance of storage capacity, deviations from the I2RS model generally appear as significant, although more limited and less frequent in the case of the GA-RR model. The latter for instance produces differences larger than $10 \%$ for $10 \%$ of the simulations whereas these errors rise to 35 and $48 \%$ for $\mathrm{GA}-\theta_{\mathrm{FC}}$ and $\mathrm{CR}$ methods. Finally, frequency-based reduction efficiencies $E_{3-\text { mth }}, E_{6-\text {-nths }}$ and $E_{12-\text { nthts }}$ are also clearly affected by the adoption of a simpler modeling approach. Departures from I2RS are, once again, more important for the GA- $\theta_{\mathrm{FC}}$ and the CR approaches, but may, nevertheless, become non-negligible in the case of the GA-RR model.
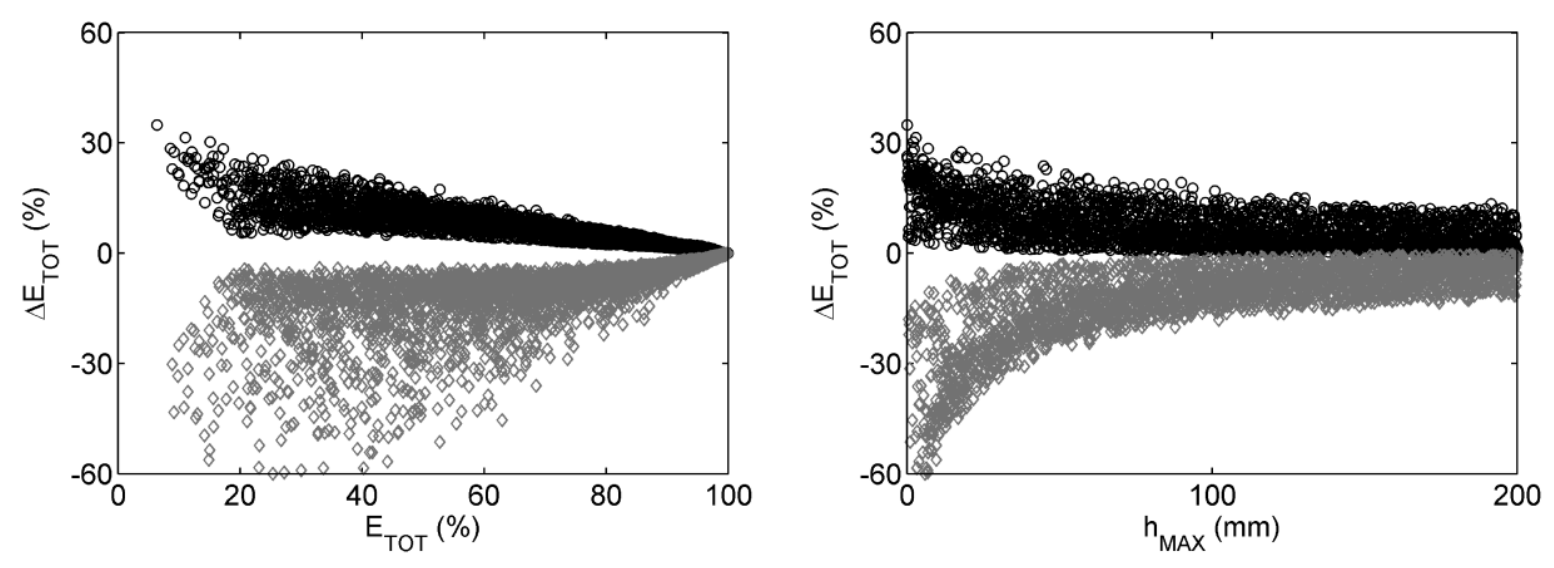

Figure 9. Percent deviations in $\mathrm{E}_{\text {TOT }}$ as function of $\mathrm{E}_{\text {TOT }}$ and $\mathrm{h}_{\mathrm{MAx}}$ for the GA equation with fixed initial water content $\mathrm{GA}-\theta_{\mathrm{FC}}$ (black circles) and the constant rate $\mathrm{CR}$ infiltration model (grey diamonds) (the figure associated with GA-RR can be found in supplementary materials)

Further analysis of simulation results (see Tables S21-24 and figures S18-20) primarily indicates that relative deviations from the reference volume reduction efficiency $\left(\Delta \mathrm{E}_{\mathrm{TOT}}\right)$ tend to increase as $\mathrm{E}_{\mathrm{TOT}}$ decreases (Kendall rank correlation coefficient $\tau=-0.69,-0.86$ and -0.80 for GA-RR, GA- $\theta_{\mathrm{FC}}$ and CR) and may become significant for SUDS with $E_{\text {TOT }}<75 \%$ (5 to $10 \%$ for GA-RR and up to $60 \%$ for the CR model). Largest errors such as the $10 \%$ shown in figure 8 are therefore associated with moderate efficiency designs. For the simplest modeling approaches (GA- $\theta_{\mathrm{FC}}$ and $\left.\mathrm{CR}\right), \Delta \mathrm{E}_{\mathrm{TOT}}$ is additionally found to increase as maximum ponding depth $\mathrm{h}_{\mathrm{MAX}}$ decreases (cf. figure 9. Note that results associated with GA-RR can be found in figure S18 and S19). For these two models, relative differences in the estimation of $T_{\text {OUT }}\left(\Delta T_{\text {OUT }}\right)$ as well exhibit a dependence on $\mathrm{E}_{\mathrm{TOT}}(\tau>0.45)$. While extreme $\Delta T_{\text {OUT }}$ value are essentially associated with very efficient design scenarios (that presumably produce significant attenuation of runoff discharge), errors may nevertheless remain significant for medium to high efficiency designs $\left(50 \%<E_{\mathrm{TOT}}<80 \%\right)$ with maximum values ranging from $40 \%$ with $\mathrm{GA}-\theta_{\mathrm{FC}}$ to $60 \%$ for the $\mathrm{CR}$ model. Finally, deviations in $E_{3 \text {-ntths }}$ and $E_{6-\text {-nths }}$ show a moderate dependence on $E_{T O T}$ (with $-0.45<\tau<-0.56$ ) whereas $\Delta E_{12-n t h s}$ remains more erratic. 


\section{CONCLUSIONS}

An improved infiltration-redistribution scheme (I2RS), based on the coupling of the Green-Ampt (GA) equation with a redistribution scheme adapted from previous studies, was introduced. The I2RS model was evaluated for both simple theoretical case studies and long-period applications under hydrologic conditions similar to those encountered in SUDS. The accuracy of infiltration rate and soil moisture predictions was checked against numerical solutions of Richards equation for seven USDA soil classes. The importance of a correct description of the temporal variability of infiltration fluxes was later assessed by comparing the results associated with the I2RS model to those computed for simpler and more usual modeling approaches, over a wide range of stormwater infiltration scenarios.

As opposed to previous rectangular profile redistribution models, that were either not tested over long rainfall periods or shown to produce increasing errors on infiltrated volumes, the I2RS model appears as a suitable option for long period applications. The redistribution scheme, originally developed by (Milly 1986), here incorporates a modification that allows for a relatively precise representation of near-surface water content and clearly helps to overcome the limitations of previous GA-based solutions. Although infiltration-rates computed with the I2RS model may slightly differ from the numerical solution of Richards equation, such deviations are believably expectable due to the approximate nature of the GA equation (Parlange et al. 2002) and nevertheless remain very limited. Given the influence evapotranspiration-related parameters on the reference simulations conducted with HYDRUS-1D, the description of this process in the I2RS model could be examined for further model improvement.

The computational efficiency of the I2RS model was found to be very satisfactory (and promising given the limitations of the current code). No convergence issues were encountered for the numerous tests associated with model evaluation. This numerical stability is a clear advantage as compared to the resolution of Richards' equation, especially when performing long period simulations, under a variety of surface boundary conditions (which is often the case in the context of urban drainage modeling).

The I2RS model also largely and systematically outperforms simpler modeling approaches for the prediction of infiltration rates. While the GA equation may be perceived as a more sophisticated method than constant rate infiltration model, the benefits associated with its adoption, under the common assumption that soil water content immediately drops to field capacity when infiltration stops, are found to be mostly negligible. Conversely, association of the GA equation with a rudimentary redistribution model, similar to the ones implemented in EPA's SWMM for rain garden modeling (Rossman 2010b), results in a noticeable improvement in the accuracy of infiltration rates predictions.

Application of the different modeling approaches over multiple stormwater infiltration scenarios primarily demonstrates that neglecting the inter- or intra-event variability of infiltration fluxes (assuming 
constant rate infiltration or neglecting the redistribution process) may significantly bias the assessment of the performance of source control systems. Rudimentary representation of the redistribution process markedly improves the estimation of the different efficiency indicators, although deviations from the I2RS model remain noticeable for some configurations. Expectedly, long term volume reduction efficiencies are generally less affected by the adoption of a simpler modeling approach than distributionbased indicators (e.g. return period associated with non-zero discharge and efficiency associated with a given return period). Here, errors associated with instantaneous infiltration-rates prediction are presumably compensated by the ability of stormwater to accumulate over soil surface, resulting in small deviations in overall infiltration volumes. As a consequence, the influence of the infiltration model also tends to be more visible for small ponding depth and moderate efficiency designs (as the storage capacity is more frequently exceeded). These results highlight the importance of selecting infiltration models in accordance with the application considered and have important implications. First, more sophisticated approaches should probably be preferred (1) when short-duration performance indicators are investigated or (2) when moderate efficiency designs (such as those focusing on small storms) are considered. Second, although small ponding depth facilities yet remain unusual, the trend toward increasingly diffuse and integrated solutions (Fletcher et al. 2014) as well impervious cover reduction could possibly require an adaptation of modeling practices.

The I2RS model is currently implemented in a relatively accessible language that already enables adaptation to deal with some of the specificities of SUDS: discharge at controlled rate through a flow limiting device, relation between infiltration area and water storage, introduction of pollutants (Sage et al. 2016). Because the model incorporates a precise description of soil moisture content, it could also be a relevant tool to simulate water balance and evapotranspiration fluxes from SUDS or other vegetated surfaces.It is however important to acknowledge the limitation of this approach in the context of SUDS modeling. First, urban soils often exhibit heterogeneities and stormwater management increasingly relies on multi-layer systems such as bioretention devices; extensions of the I2RS model to heterogeneous soil domain should therefore be considered. Similarly, the implementation of a zero pressure or mixed boundary condition at the bottom of soil profile should presumably be carried out for facilities that. receive very large amounts of stormwater or when the water table does not lie far below soil surface (Locatelli et al. 2015).

More generally, the assumption of a strictly one-dimensional flow, adopted in both I2RS and HYDRUS1D, may not always be appropriate(Freni et al. 2009). Besides, the ability of Richards' equation to describe infiltration fluxes is still the subject of debate in watershed hydrology due to the complex nature of soil (Beven 2004; McDonnell et al. 2007). The later nonetheless remain the most robust solution to simulate the effect of soil moisture redistribution on infiltration fluxes. 


\section{SUPPLEMENTAL DATA}

Figures. S1-S20 and tables S1-S24 are available online in the ASCE Library (ascelibrary.org).

\section{DATA AVAILABILITY STATEMENT}

All data, models, or code that support the findings of this study are available from the corresponding author upon reasonable request.

\section{REFERENCES}

Abi Aad, M. P., Suidan, M. T., and Shuster, W. D. (2010). "Modeling Techniques of Best Management Practices: Rain Barrels and Rain Gardens Using EPA SWMM-5." Journal of Hydrologic Engineering, 15(6), 434-443.

Akan, A. O. (2013). "Preliminary Design Aid for Bioretention Filters." Journal of Hydrologic Engineering, 18(3), 318-323.

Barry, D. A., Parlange, J.-Y., Sander, G. C., and Sivaplan, M. (1993). "A class of exact solutions for Richards' equation." Journal of Hydrology, 142(1-4), 29-46.

Beven, K. (2004). “Robert E. Horton's perceptual model of infiltration processes.” Hydrological Processes, John Wiley \& Sons, Ltd., 18(17), 3447-3460.

Bressy, A., Gromaire, M. C., Lorgeoux, C., Saad, M., Leroy, F., and Chebbo, G. (2014). "Efficiency of source control systems for reducing runoff pollutant loads: Feedback on experimental catchments within Paris conurbation." Water Research, 57, 234-246.

Brooks, R., and Corey, A. (1964). "Hydraulic properties of porous media." Hydrology Papers, Colorado State University, 3, $37 \mathrm{pp}$.

Browne, D., Deletic, A., Mudd, G. M., and Fletcher, T. D. (2008). "A new saturated/unsaturated model for stormwater infiltration systems.” Hydrological Processes, 22, 4838-4849.

Brunetti, G., Šimůnek, J., Bogena, H., Baatz, R., Huisman, J. A., Dahlke, H., and Vereecken, H. (2019). "On the Information Content of Cosmic-Ray Neutron Data in the Inverse Estimation of Soil Hydraulic Properties." Vadose Zone Journal, 18(1).

Choisnel, E. (1988). "Estimation de l'évapotranspiration potentielle à partir des données météorologique [Estimating potential evapotranspiration from meteorological data]." La Météorologie 7ème série.

Clapp, R. B., Hornberger, G. M., and Cosby, B. J. (1983). "Estimating spatial variability in soil moisture with a simplified dynamic model.” Water Resources Research, 19(3), 739-745.

Corradini, C., Melone, F., and Smith, R. E. (1997). "A unified model for infiltration and redistribution during complex rainfall patterns.” Journal of Hydrology, 192, 104-124. 
Criss, R. E., and Winston, W. E. (2008). "Do Nash values have value? Discussion and alternate proposals." Hydrological Processes, 22(14), 2723-2725.

Dagan, G., and Bresler, E. (1983). "Unsaturated flow in spatially variable fields: 1. Derivation of models of infiltration and redistribution.” Water Resources Research, 19, 413.

Dussaillant, A., Cozzetto, K., Brander, K., and Potter, K. (2003). "Green-Ampt Model Of A Rain Garden And Comparison To Richards Equation Model." Transactions on Ecology and the Environment, WIT Press, 67, 10.

Fatichi, S., Vivoni, E. R., Ogden, F. L., Ivanov, V. Y., Mirus, B., Gochis, D., Downer, C. W., Camporese, M., Davison, J. H., Ebel, B., Jones, N., Kim, J., Mascaro, G., Niswonger, R., Restrepo, P., Rigon, R., Shen, C., Sulis, M., and Tarboton, D. (2016). "An overview of current applications, challenges, and future trends in distributed process-based models in hydrology." Journal of Hydrology, 537, 45-60.

Fletcher, T. D., Andrieu, H., and Hamel, P. (2013). "Understanding, management and modelling of urban hydrology and its consequences for receiving waters: A state of the art." Advances in Water Resources, 51, 261-279.

Fletcher, T. D., Shuster, W., Hunt, W. F., Ashley, R., Butler, D., Arthur, S., Trowsdale, S., Barraud, S., Semadeni-Davies, A., Bertrand-Krajewski, J.-L., Mikkelsen, P. S., Rivard, G., Uhl, M., Dagenais, D., and Viklander, M. (2014). "SUDS, LID, BMPs, WSUD and more - The evolution and application of terminology surrounding urban drainage.” Urban Water Journal, Taylor \& Francis, 1-18.

Freni, G., Mannina, G., and Viviani, G. (2009). "Urban runoff modelling uncertainty: Comparison among Bayesian and pseudo-Bayesian methods." Environmental Modelling and Software, 24, 1100-1111.

Freyberg, D. L., Reeder, J. W., Franzini, J. B., and Remson, I. (1980). "Application of the GreenAmpt Model to infiltration under time-dependent surface water depths." Water Resources Research, 16(3), 517.

Gardner, W. R., Hillel, D., and Benyamini, Y. (1970). "Post-Irrigation Movement of Soil Water: 1. Redistribution.” Water Resources Research, 6(3), 851-861.

Govindaraju, R. S., and Levent Kavvas, M. (1993). "Development of an approximate model for unsaturated flow with root water uptake under rectangular water content profiles assumption." Journal of Hydrology, 146(0), 321-339.

Gowdish, L., and Muñoz-Carpena, R. (2009). "An Improved Green-Ampt Infiltration and Redistribution Method for Uneven Multistorm Series." Vadose Zone Journal.

Green, W. H., and Ampt, G. A. (1911). "Studies on Soil Phyics." The Journal of Agricultural Science, $4(1), 1-24$.

Heasom, W., Traver, R. G., and Welker, A. (2006). "Hydrologic modeling of a bioinfiltration best management practice." Journal of the American Water Resources Association, 42, 1329-1347. 
Her, Y., Jeong, J., Arnold, J., Gosselink, L., Glick, R., and Jaber, F. (2017). “A new framework for modeling decentralized low impact developments using Soil and Water Assessment Tool."

Environmental Modelling \& Software, 96, 305-322.

Lai, W., Ogden, F. L., Steinke, R. C., and Talbot, C. A. (2015). "An efficient and guaranteed stable numerical method for continuous modeling of infiltration and redistribution with a shallow dynamic water table." Water Resources Research, n/a-n/a.

Lee, R., Traver, R., and Welker, A. (2013). "Continuous Modeling of Bioinfiltration Storm-Water Control Measures Using Green and Ampt.” Journal of Irrigation and Drainage Engineering, American Society of Civil Engineers, 139(12), 1004-1010.

Locatelli, L., Mark, O., Mikkelsen, P. S., Arnbjerg-Nielsen, K., Wong, T., and Binning, P. J. (2015). "Determining the extent of groundwater interference on the performance of infiltration trenches." Journal of Hydrology, 529, Part, 1360-1372.

Lynn, T. J., Nachabe, M. H., and Ergas, S. J. (2018). "SWMM5 Unsaturated Drainage Models for Stormwater Biofiltration with an Internal Water Storage Zone." Journal of Sustainable Water in the Built Environment, 4(1), 04017018.

Markar, M. S., and Mein, R. G. (1987). "Modeling of evapotranspiration from homogenous soils." Water Resources Research, 23(10), 2001-2007.

McDonnell, J. J., Sivapalan, M., Vaché, K., Dunn, S., Grant, G., Haggerty, R., Hinz, C., Hooper, R., Kirchner, J., Roderick, M. L., Selker, J., and Weiler, M. (2007). "Moving beyond heterogeneity and process complexity: A new vision for watershed hydrology." Water Resources Research.

Milly, P. C. D. (1986). "An event-based simulation model of moisture and energy fluxes at a bare soil surface.” Water Resources Research, 22, 1680.

Morbidelli, R., Corradini, C., Saltalippi, C., Flammini, A., and Rossi, E. (2011). "Infiltration-soil moisture redistribution under natural conditions: experimental evidence as a guideline for realizing simulation models." Hydrology and Earth System Sciences, 15(9), 2937-2945.

Morel-Seytoux, H. J., Meyer, P. D., Nachabe, M., Touma, J., Van Genuchten, M. T., and Lenhard, R. J. (1996). "Parameter equivalence for the Brooks-Corey and van Genuchten soil characteristics: Preserving the effective capillary drive.” Water Resources Research, 32, 1251-1258.

Ogden, F. L., Lai, W., Steinke, R. C., Zhu, J., Talbot, C. A., and Wilson, J. L. (2015). “A new general 1-D vadose zone flow solution method: 84 YEARS AFTER RICHARDS: A NEW VADOSE ZONE SOLUTION METHOD.” Water Resources Research, 51(6), 4282-4300.

Ogden, F. L., and Saghafian, B. (1997). “Green and Ampt Infiltration with Redistribution.” Journal of Irrigation and Drainage Engineering, 123(5), 386-393.

Parlange, J. Y., Barry, D. A., and Haverkamp, R. (2002). "Explicit infiltration equations and the Lambert W-function.” Advances in Water Resources, 25(8-12), 1119-1124. 
Rawls, W. J., Brakensiek, D. L., and Saxton, K. E. (1982). "Estimation of Soil Water Properties." Transactions of the ASAE, 25, 1316-1320 \& 1328.

Richards, L. A. (1931). "CAPILLARY CONDUCTION OF LIQUIDS THROUGH POROUS MEDIUMS.” Physics, American Institute of Physics, 1(5), 318-333.

Romero, C. C., and Dukes, M. D. (2015). "Review of Turfgrass Evapotranspiration and Crop Coefficients." ASABE, 1-25.

Rosa, D. J., Clausen, J. C., and Dietz, M. E. (2015). "Calibration and Verification of SWMM for Low Impact Development." JAWRA Journal of the American Water Resources Association, 51(3), 746-757.

Rossman, L. A. (2010a). "Storm water management model, user's manual version 5.0, report EPA/600/R-05/040.” National Risk Management Research Laboratory, Office of Research and Development, U.S. Environmental Protection Agency, Cincinnati, OH.

Rossman, L. A. (2010b). "Modeling Low Impact Development Alternatives with SWMM.” Journal of water management modelling.

Sage, J. (2016). "Hydrologic performance of stormwater management strategies : optimization for on-site pollution control." Theses, Université Paris-Est.

Sage, J., Berthier, E., and Gromaire, M.-C. (2015). "Stormwater Management Criteria for On-Site Pollution Control: A Comparative Assessment of International Practices." Environmental Management, Springer US, 56(1), 66-80.

Sage, J., Berthier, E., and Gromaire, M.-C. (2016). "Towards the production of guidelines to support the design of stormwater management practices for on- site pollution control." NOVATECH 2016, Lyon, France.

Salvadore, E., Bronders, J., and Batelaan, O. (2015). "Hydrological modelling of urbanized catchments: A review and future directions." Journal of Hydrology, 529, 62-81.

Schaefli, B., and Gupta, H. V. (2007). "Do Nash values have value?” Hydrological Processes, 21, 20752080 .

Šimůnek, J., Sejna, M., Saito, H., Sakai, M., and van Genuchten, M. Th. (2009). The HYDRUS-1D software package for simulating the one-dimensional movement of water, heat, and multiple solutes in variablysaturated media. Version 4.08. HYDRUS Softw. Ser. 3.

Smith, R. E., Corradini, C., and Melone, F. (1993). "Modeling infiltration for multistorm runoff events." Water Resources Research, 29, 133-144.

Stewart, R. D., Rupp, D. E., Najm, M. R. A., and Selker, J. S. (2013). "Modeling effect of initial soil moisture on sorptivity and infiltration." Water Resources Research, 49, 7037-7047.

Struthers, I., Hinz, C., and Sivapalan, M. (2006). "A multiple wetting front gravitational infiltration and redistribution model for water balance applications." Water Resources Research, 42. 
Talbot, C. A., and Ogden, F. L. (2008). "A method for computing infiltration and redistribution in a discretized moisture content domain.” Water Resources Research, 44(8).

Triadis, D., and Broadbridge, P. (2012). "The Green-Ampt limit with reference to infiltration coefficients." Water Resources Research, 48(7).

Warrick, A. W., and Broadbridge, P. (1992). "Sorptivity and macroscopic capillary length relationships." Water Resources Research, 28, 427.

White, I., and Sully, M. J. (1987). "Macroscopic and microscopic capillary length and time scales from field infiltration." Water Resources Research, 23, 1514. 